\title{
WestVirginiaUniversity
}

THE RESEARCH REPOSITORY @ WVU

Graduate Theses, Dissertations, and Problem Reports

2003

\section{Adjustment to relocation to an assisted living facility}

Lisa Whipple Drozdick

West Virginia University

Follow this and additional works at: https://researchrepository.wvu.edu/etd

\section{Recommended Citation}

Drozdick, Lisa Whipple, "Adjustment to relocation to an assisted living facility" (2003). Graduate Theses, Dissertations, and Problem Reports. 1822.

https://researchrepository.wvu.edu/etd/1822

This Dissertation is protected by copyright and/or related rights. It has been brought to you by the The Research Repository @ WVU with permission from the rights-holder(s). You are free to use this Dissertation in any way that is permitted by the copyright and related rights legislation that applies to your use. For other uses you must obtain permission from the rights-holder(s) directly, unless additional rights are indicated by a Creative Commons license in the record and/ or on the work itself. This Dissertation has been accepted for inclusion in WVU Graduate Theses, Dissertations, and Problem Reports collection by an authorized administrator of The Research Repository @ WVU.

For more information, please contact researchrepository@mail.wvu.edu. 
Adjustment to Relocation to an Assisted Living Facility

Lisa Whipple Drozdick

\begin{abstract}
Dissertation submitted to the College of Arts and Sciences At West Virginia University in partial fulfillment of the requirements

for the degree of
\end{abstract}
Doctor of Philosophy
in
Clinical Psychology

\title{
Barry Edelstein, Ph. D., Chair \\ Martin Boone, Ph.D. \\ Rick Briggs, Ed.D. \\ Stanley Cohen, Ph.D. \\ Daniel McNeil, Ph.D. \\ Department of Psychology
}

Morgantown, West Virginia

2003

Keywords: Older Adults, Relocation, Assisted Living, Adjustment

Copyright 2003 Lisa Whipple Drozdick 


\section{Abstract \\ Adjustment to Relocation to an Assisted Living Facility \\ Lisa Whipple Drozdick}

Assisted living has become the fastest growing senior housing alternative for older adults, yet little research has been conducted with residents of assisted living. Relocation involves a major life change and is associated with health problems, poor adjustment, and increased mortality. Research on relocation into nursing homes suggests declines in health and psychological well-being frequently follow relocation and are greatest one to two months following entry into the facility. Control over the decision to relocate and control within the facility following relocation have been related to physical and mental health. Assisted living residents are similar to nursing home residents so similar patterns of adjustment, though potentially less severe, are likely to be seen in assisted living residents. The current study compares 18 residents of assisted living with 19 community dwelling older adults at three times on various aspects of adjustment, including physical and functional health, depression, life satisfaction, affect, and anxiety over a three month period following relocation in the assisted living group. Assisted living residents did not show the expected decline over the first several months following relocation, perhaps due to health stabilization. However, residents of assisted living did report lower life satisfaction and exhibited greater disparity between actual and desired control than community residents. Moreover, both the community dwelling older adults and residents of assisted living were clinically distressed on measures of depression and anxiety. The groups did not differ on the amount of change in health and psychological well being experienced over time, demonstrating similar rates of decline over time. Decisional control was negatively related to depression and positively related to physical and functional health. In addition, actual environmental control was positively related to physical and functional health and life satisfaction and negatively related to depression, negative affect, and anxiety. Health has been related to depression and life satisfaction, and the significant correlations between health and the adjustment variables suggests that health played a role in the current study. Overall, the study demonstrated the importance of control, social support, and health of adjustment to relocation into assisted living facilities. Limitations and future directions are included. 
Acknowledgements

Adjustment to Assisted Living iii

The completion of this project would not have been possible without the efforts of several outstanding individuals. Foremost, I would like to thank Barry Edelstein, for his patience, understanding, encouragement, and continual support. His professional guidance helped shape both this project and numerous aspects of my career. He continues to be a guiding force to me and to the field of clinical gerontology. My sincere appreciation also goes to my committee members, Martin Boone, Rick Briggs, Stan Cohen, and Daniel McNeil whose assistance made the completion of this project possible. It has been an honor to work with each of them.

Several other individuals helped mold this project into its current form. My supervisors, Stephen Holliday, Pete Donahoe, and Eric Rolfhus all encouraged me to not only complete this project, but went out of their way to make it possible to complete data collection and analysis. Tom Cayton also deserves mention for providing the extra push to keep me on track. Finally, Harriett Wiygul deserves special mention for her editorial assistance, the often unsung heroes of a manuscript are the editors - APA and I are grateful!

I would also like to thank Glendon Starr and Jean Whipple, my grandmother and mother, whose unfettered faith in me and assistance in recruiting subjects was invaluable. They are both amazing women whose example and guidance in life are unparalleled. Also, Bill Whipple, my father, who kept me focused and on track by continually reminding me to work by asking when he should plan to take vacation time Well Dad, take it this year!

I would also like to acknowledge each of the individuals who participated in this study. Although I cannot name them, each one provided valuable information and gave freely of their time, often during a difficult period of their life, to answer my questions. Given the personal nature of many of the questions, I cannot thank them enough for their disclosure.

Finally, I would like to thank the people who mean the most to me and for whom the completion of this project is invaluable, my husband Keller, and children Hayley and Aidan. Keller's unbelievable support and cheers throughout the course of this project prevented it from being neglected. Hayley and Aidan, both of whom arrived during this project, may not understand why Mommy was gone so much or working all the time but their smiles and hugs made each day! Thank you and I look forward to more time at home! 


\section{Table of Contents}

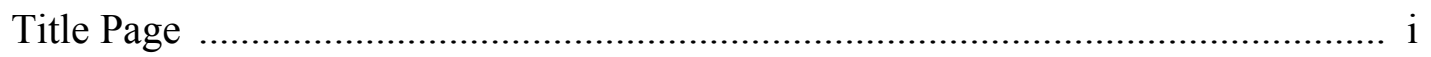

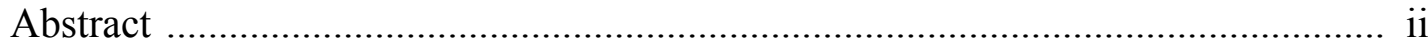

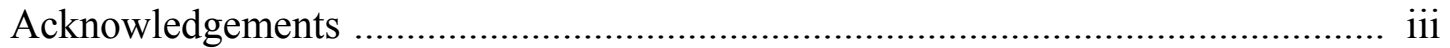

Table of Contents ....................................................................................... iv

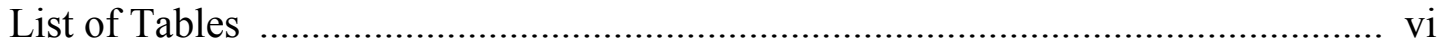

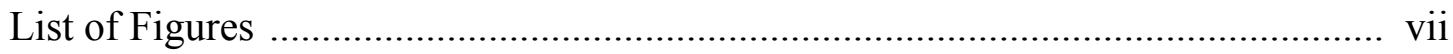

List of Appendices ................................................................................. viii

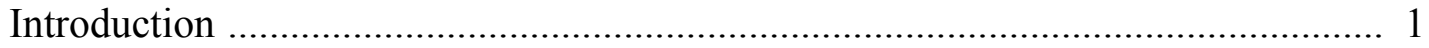

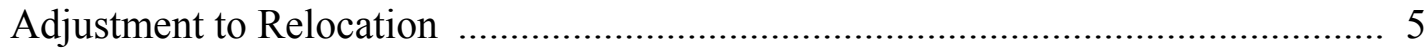

Research on Adjustment to Relocation into Nursing Homes .................... 6

Research on Assisted Living ............................................................. 9

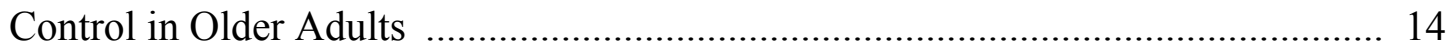

Decisional Control Over Relocation in Older Adults ....................................... 21

Statement of Problem ....................................................................................... 23

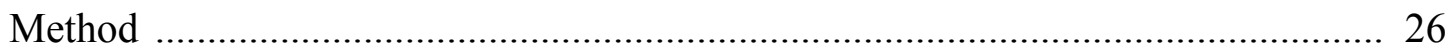

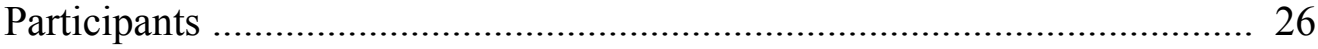

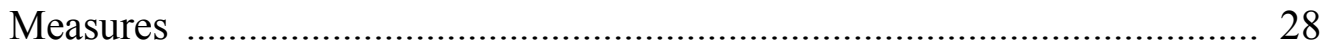

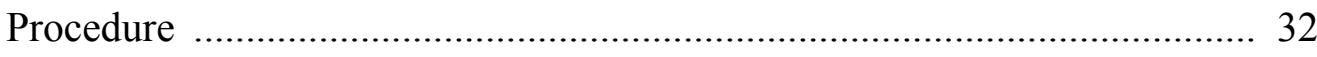

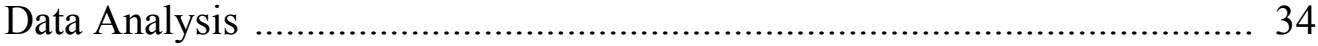

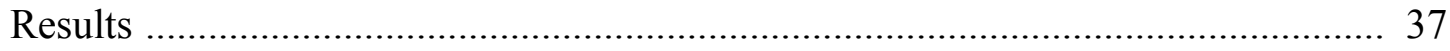

Demographic and Qualitative Analyses ............................................. 37

Hypothesis 1: Adjustment Over Time ................................................. 38

Hypothesis 2: Group Differences on Adjustment Variables ..................... 39

Hypothesis 3: Desired Versus Actual Control ........................................ 39

Hypothesis 4: Physical and Psychological Changes Over Time ................ 40

Hypothesis 5: Control and Adjustment ................................................ 40

Hypothesis 6: Control and Health ......................................................... 41

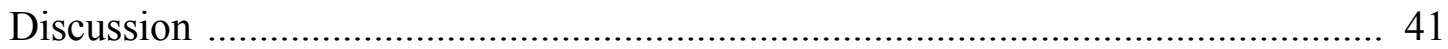

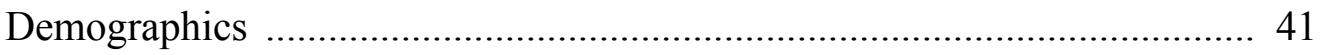


Adjustment to Assisted Living v

Decisional Involvement Among Assisted Living Residents 42

Adjustment Over Time …………………………………....................... 44

Group Differences on Adjustment Variables ................................................ 45

Desired Versus Actual Control .................................................................. 47

Physical and Psychological Health Changes Over Time .............................. 48

Control and Adjustment ....................................................................... 48

Control and Health .............................................................................. 49

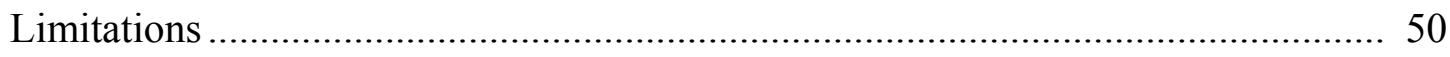

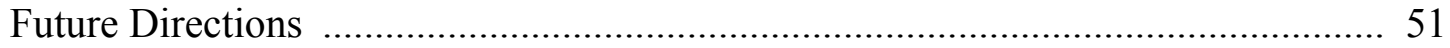

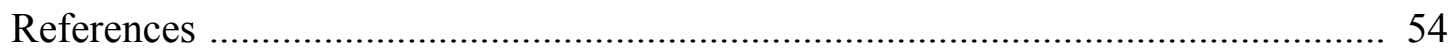

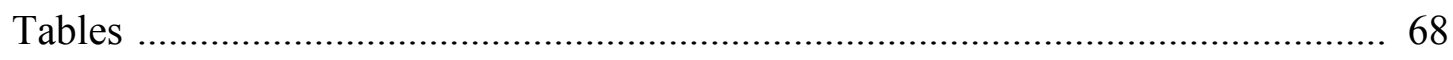

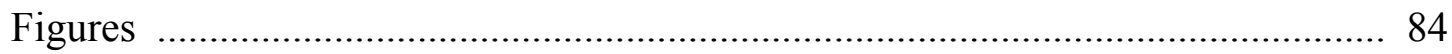

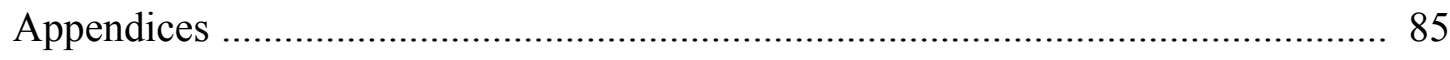

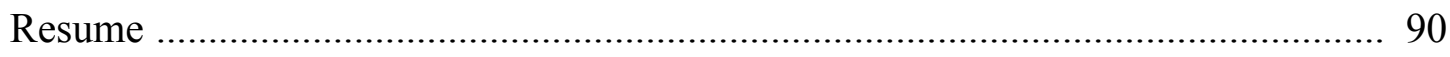




\section{List of Tables}

Adjustment to Assisted Living vi

Table 1 Characteristics of Assisted Living and Nursing Home Residents ......................... 68

Table $2 \quad$ Reasons for Assisted Living Residents Nonparticipation .................................... 69

Table 3 Number of Participants Completing Evaluations at Each Time Period, by Group ... 70

Table 4 Demographic Characteristics of the Assisted Living and Community Dwelling

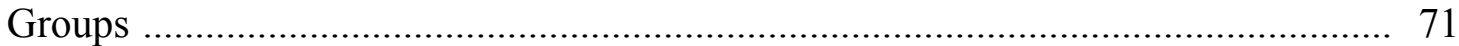

Table 5 Percent of Assisted Living Residents Reporting Various Responses on the

Decisional Control Questionnaire

Table 6 Percent of Assisted Living Sample Reporting Various Reasons for Entering

Assisted Living Facilities

Table 7 Percent of Community Sample Reporting Various Circumstances Under Which

They Would Consider Entering Assisted Living Facilities ................................ 74

Table 8 Variable Means, Standard Deviations, and Ranges, by Group and Time Period ...... 75

Table 9 Results of Repeated Measures ANOVA's, by Group .......................................... 76

Table $10 \quad$ Mean Differences Between Groups on Adjustment Variables, by Time Period ....... 77

Table 11 Mean Differences Between Groups on Control Discrepancy, by Time Period ......... 78

Table 12 Mean Differences Between Groups on Adjustment Change Scores, by Time

Period

Table 13 Correlations Between Decisional Control and Adjustment Variables, by Time

Period

Table 14 Correlations Between Desired and Experienced Control and Adjustment

Variables, by Time Period

Table 15 Correlations Between Perceived Decisional Control and Health Variables, by

Time Period

Table 16 Correlations Between Desired and Expected Control and Health Variables, by

Time Period 
Adjustment to Assisted Living vii

List of Figures

Figure 1 Graphs of Adjustment Variables Over the Three Time Periods, by Group ............... 84 
Adjustment to Assisted Living viii

\section{List of Appendices}

Appendix A

Demographic Questionnaire ........................................................... 85

Appendix B

Questionnaire on Decisional Involvement 86

Appendix C

Perceived Decisional Control Questionnaire

Appendix D

Self-Rated Health Questionnaire 88

Appendix E

Geriatric Depression Scale 89 
Adjustment to Assisted Living 1

Adjustment to Relocation to an Assisted Living Facility

As the number of older adults has grown over the past decades, so have the number of housing options available to the elderly. Traditionally, older adults who were unable or did not desire to live alone were taken in and cared for by family members. Those who had no family were frequently placed in long-term care facilities. However, the availability of familial caregivers today is often limited due to smaller family size and increased geographic distance between family members. For these reasons, as well as the increased personal wealth of seniors, the demand for alternative housing choices for older adults has increased (Keslosky \& Stevens, 1999). This need is particularly high among seniors who do not own and reside in their own home because they typically spend more money on housing than on food, healthcare, clothing, or transportation (Gilderbloom \& Mullins, 1995). Although personal wealth has increased among older adults, those who require specialized housing are likely to face financial hardship. Options for older adults seeking non-community housing include retirement communities, congregate care facilities, assisted living facilities, continuing care residential communities, and board and care homes, and offer varying degrees and levels of care. Currently, with an annual growth rate of 25 to 30 percent, the fastest growing housing alternative for older adults is assisted living facilities (Hawes, Phillips, \& Rose, 2000; Keslosky \& Stevens, 1999).

Assisted living facilities provide care and physical assistance to residents in a homelike setting and are frequently described as a step between living at home and living in a nursing home. They differ from nursing homes in the amount of care they provide (i.e., less than 24-hour medical supervision and less assistance with personal and medical needs) and in their emphasis on resident independence and autonomy. Approximately 1.15 million people, the majority of whom are older adults, currently reside in assisted living facilities (National Center for Assisted 
Adjustment to Assisted Living 2 Living [NCAL], 1998). With increasing numbers of facilities under construction, an average occupancy rate of 95.7 percent (Keslosky \& Stevens, 1999), and the continuing growth of the older adult population, demand for assisted living facilities will likely remain high for many years.

Despite the popularity of assisted living, little research has been conducted with residents of these facilities, including research on the claims of assisted living as a step between nursing homes and private residences. Comparisons of residents in assisted living and residents in nursing homes show that demographically there are few differences between the two groups. Residents are similar in age, gender, and marital status. (Frytak, Kane, Finch, Kane, and MaudeGriffin, 2001; Kane \& Wilson, 1993; Pruchno \& Rose, 2000). However, assisted living residents on average have a higher monthly income and attained a higher level of education than residents of nursing homes (Pruchno \& Rose, 2000). In addition, they are less cognitively and functionally impaired, and less physically frail than nursing home residents (Kane, Huck, Frytak, Kane \& Finch, 1999 as cited in Frytak et al., 2001). See Table 1 for a comparison of the characteristics of assisted living and nursing home residents. Interestingly, Frytak et al. (2001) found no difference in changes over time in physical functioning, psychological well-being, or pain and discomfort levels between residents of nursing homes and residents of assisted living. Moreover, baseline levels of psychological well-being and pain and discomfort levels were similar in the two groups. Only disability differed between groups at baseline, with nursing home residents being more physically and cognitively disabled than residents of assisted living facilities. Although differences in physical health and cognitive ability exist between the two groups of residents, Pruchno and Rose suggest that the ability to pay, not physical or cognitive status, often determines which type of housing facility an older adult relocates to as his or her need for care 
Adjustment to Assisted Living 3 increases. However, as more states fund assisted living through Medicaid and Medicare, this disparity may diminish.

Relocation, regardless of destination, involves a major life change for an individual, similar to marriage, divorce, and retirement, and is widely considered to be stressful to individuals (Brammer, 1992; Kas1, 1972; Seligman, 1975). Such life events have been associated with increased health problems, poor adjustment, and increased mortality (Birren, 1965; Rowland, 1977; Tobin, 1989). Within a five year period, roughly one-third of people over the age of 65 change residences (Maddox et al., 1987). Moreover, Wilmoth (1998) found that after the age of 75 , the chance of experiencing a change in living arrangement increases dramatically form roughly 10 percent of 75 -year olds and 25 percent of 85 year olds relocating, with the risk of institutionalization (i.e., entry into an environment providing specialized services, such as a nursing home, assisted living facility, or hospital) increasing with age. Moving may be particularly stressful for the older adult as it often occurs after an individual has experienced previous losses (e.g., death of spouse or friends, health deterioration) and psychological, social, and financial resources are diminished (Birren; Brand \& Smith, 1974; Mikhail, 1992; Nay, 1995). Nearly 80 percent of individuals relocating into assisted living facilities and approximately one-third of individuals relocating to nursing homes come from residential homes (Gabrel \& Jones, 2000; Hawes, Phillips, \& Rose, 2000). Relocation into a controlled environment, such as an assisted living or long-term care facility, may be particularly stressful, due to the additional loss of personal independence. As the population of older adults continues to grow, more individuals will face the transition from living in the community to residing in a senior care facility.

Several risk factors for institutionalization have been identified using nursing home 
Adjustment to Assisted Living 4 samples (Grayson, Lubin, \& Van Whitlock, 1995). Similar studies have not been conducted with assisted living residents but results are likely applicable to this group given their demographic and medical similarity to nursing home residents. The studies identifying risk factors are useful in identifying at-risk community dwelling older adults, who are more similar to current nursing home residents than other community-dwelling older adults (Tobin \& Lieberman, 1976). In an analysis of current nursing home residents, several factors were found to predict nursing home placement: increased age, Euro-American ethnicity, living alone, having few non-familial supports, having limitations in activities of daily living, experiencing prior hospitalizations or nursing home admissions, and expressing limited control over future health (Wolinsky, Callahan, Fitzgerald, \& Johnson, 1992). Not surprisingly, assisted living and nursing home residents share many of these characteristics. The typical nursing home resident is an 83-year old widowed (or single) Caucasian female with minimal financial resources who is facing a serious health problem (Sahyoun, Pratt, Lentzner, Dey, \& Robinson, 2001). The typical assisted living resident is an 85-year old widowed (or single) Caucasian female who is mobile but requires assistance with at least one instrumental activity of daily living (Hawes, Rose, \& Phillips, 1999; NCAL, 1998). One-third of individuals entering a nursing home come from acute care hospitals (Kane, Ilston, Kane, \& Nyman, 1990), and one quarter of individuals entering assisted living relocate from acute care hospitals or nursing homes (NCAL, 1998). These findings emphasize the role health factors play in residential relocation decisions and participation in relocation decisions.

In studies of involvement in discharge planning by elderly patients of acute care hospitals, only 50 percent of older patients reported being involved in relocation decisions (Coulton, Dunkle, Goode, \& MacKintosh, 1982; Minichiello, 1986). Family members and physicians often make or heavily influence these decisions (Coulton et al., 1982; Nay, 1995). In 
Adjustment to Assisted Living 5 addition, many older individuals report the decision as forced (i.e., no other choices) or state that all possible choices were negative. Hawes, Phillips, and Rose (2000) found that 70 percent of individuals entering assisted living facilities made the decision to relocate with the help of someone else, typically their family $(90.5 \%)$ or personal physician $(17.7 \%)$. However, only 52 percent of those individuals reported they had complete or almost complete control over the decision and 25 percent reported little or no control over the decision. Since choice in relocation has been found to be related to adjustment in relocation to retirement communities, low-income housing for the elderly, and congregate housing for the elderly (Armer, 1993; Armer 1996; Baglioni, 1989; Beaver, 1979; Timko \& Moos, 1989), individuals not involved in the decision to relocate may be at risk for poorer outcomes. Further, research demonstrating the positive effects of control (i.e., the ability to manipulate some aspect of the environment) on both physical and psychological health (Rodin, 1986a) suggests that the loss of decisional control (i.e., ability to choose from several alternatives) regarding relocation and control within the senior care facility may place older adults at risk for poorer physical and psychological health following relocation.

\section{Adjustment to Relocation}

As previously stated, few studies have been conducted on assisted living facilities or the residents of these facilities. However, research on relocation of older adults in general, and on relocation into nursing homes, may provide some guidance into the investigation of relocation into assisted living. Given the similar increase in supervision and decrease in independence found in both nursing homes and assisted living facilities, relocation into an assisted living facility may have a similar impact on individuals as that experienced by individuals relocating into nursing homes. Several studies suggest that health and degree of control post-relocation heavily influence the impact of relocation (Baglioni, 1989; Kasl \& Rosenfield, 1980). Since the 
Adjustment to Assisted Living 6

move into assisted living generally follows a decline in physical or mental health, the effects of relocation are likely to be more negative than relocation within the community or to retirement communities, which do not typically involve such declines in health. In addition, relocation to assisted living is potentially less negative then relocation to a nursing home, which typically involves a significant decline in health status. Moreover, the marketing of assisted living communities as housing alternatives for frail elderly needing additional care, but not skilled nursing care may have created a group of older adults who are physically healthier than nursing home residents but more dependent than community dwelling older adults. Therefore, older adults relocating into assisted living may exhibit similar, though potentially less severe, adjustment patterns as those relocating to nursing homes (Pruchno \& Rose, 2001). Given the lack of research on assisted living, and the similarity between nursing home and assisted living residents, the research on adjustment to relocation into nursing homes will be described, followed by a review of the few studies conducted with residents of assisted living. $\underline{\text { Research on Adjustment to Relocation into Nursing Homes }}$

Carmago and Preston (1945) were the first to publish a formal study on relocation to long-term care facilities. They found that the mortality rate among relocated older adults was 2-11 times higher than the mortality rate among community-dwelling older adults, with $16 \%$ of patients dying within the first month and $46 \%$ within the first year. Much of the early research on relocation focused on mortality and the negative physical effects of relocation (Danermark \& Ekström, 1990). Like Carmago and Preston, early studies demonstrated a higher rate of death during the first month following relocation in older adults when compared to older adults remaining in the community (Rowland, 1977). However, research conducted since these early studies has produced conflicting results. Some studies have shown an increase in mortality 
Adjustment to Assisted Living 7 (Aldrich \& Mendkoff, 1963; Pablo, 1977) and other studies have found no increase in mortality following relocation (Markson \& Cummings, 1976; Watson \& Buerkle, 1976). In a comprehensive review of studies examining the effects of relocation on mortality, Borup (1983) examined pre-relocation health information and found that individuals who were relocating had poorer physical health than non-relocating individuals. This is not surprising as individuals moving into nursing homes or homes of relatives are likely to have diminished health requiring them to move to a more restrictive or supervised environment. Therefore, individual health variables influenced findings in relocation studies more than the actual move. Borup concluded that relocation may be stressful to an individual but does not hasten death. In other words, death was caused by pre-existing medical conditions in relocated individuals not by relocation. Moreover, Kasl (1972) suggested that the impact of relocation is unclear with adverse reactions related to many factors other than relocation, including health, preparation for relocation, and changes in social support. While the debate over the effect of relocation on mortality continues, attention to other effects of relocation has developed.

The early studies that utilized mortality as their main measure of adjustment concluded that older adults who died demonstrated poorer adjustment than those who survived. Although mortality is an important index of adjustment, it offers no information on the psychological, social, and physical adjustment to relocation. More recent research has explored psychological (e.g., quality of life), social (e.g., number of activities), and other aspects of adjustment, in addition to mortality. Measures of adjustment vary according to the specific interests of the particular researcher but typically involve measures of health, life satisfaction, and morale (Coleman, 1990). The more recent studies on relocation have provided valuable insight into the adjustment process. 
Adjustment to Assisted Living 8

Several variables related to relocation have been found to influence adjustment to relocation. Borup (1982) compared three groups of nursing home residents: those who experienced a radical move (i.e., a move involving no preparation and a significant change in social and physical environments), those who experienced a moderate move (i.e., a move involving a moderate change in the physical environment), and a non-moving control group. He found that there was no difference in health or mortality between the groups either 3 or 6 months after the move. In contrast, Bourestom and Tars (1974), utilizing three similarly defined groups, found that individuals who experienced a radical move had significantly higher rates of dependency, depression, and mortality than the control group at 1 month following the move. However, no longer-term adjustment data were available. In a review of six studies, Grant, Skinkle, and Lipps (1992) found the results of the studies to be contradictory, with results indicating increases, decreases, and no changes in psychological and health variables following relocation. Similar conflicting results were found in regard to functional status (e.g., ability to provide self-care). Grant et al. concluded that relocating to a new facility rarely impacts residents' performance on activities of daily living but that no universal statements regarding the impact of relocation to a nursing home could be made. Moreover, Lawton and Yaffe (1970) found a decrease in functional status as a result of relocation in their study. Overall, it appears that while relocation to a nursing home may have some negative effects on physical and mental health, at least in the first month, the exact impact of relocation on health is unclear.

Psychological factors, such as life satisfaction, depression and anxiety, have been studied less frequently than health variables in the relocation literature. Grant et al. (1992) conducted a study on inter-institutional moves among frail, elderly, nursing home residents. Relocated residents were rated as more distressed by the nursing staff than non-relocated controls 
Adjustment to Assisted Living 9 immediately following the move. However, differences in distress did not exist by three months post-move. Residents who were interviewed for this research expressed worry prior to the move and adjustment problems up to 1 month following the move. In addition, Kasl and Rosenfield (1980) found that older adults forced to relocate to federal subsistence housing had greater depression and anxiety than non-relocated residents. Brand and Smith (1974) found greater declines in life satisfaction among people relocated involuntarily. Measurements of adjustment are also affected by the recency of relocation. The first 6-8 weeks following relocation appear to be the most difficult for newly admitted residents (Mikhail, 1992; Tobin \& Lieberman, 1976). Kasl and Rosenfield also suggested that the first few months following relocation were more difficult for residents. They divided adjustment into two categories, short-term adjustment and long-term adaptation, to describe the impact of the first month of residency. This first month phenomenon may help explain differences in studies whose results were obtained at different points in time following admission to a long-term care facility.

Overall, the research on adjustment to nursing home relocation shows declines in health and psychological functioning following relocation. However, it is not clear if relocation, in and of itself, or pre-existing health factors related to the need for relocation lead to the declines. Clear patterns of adjustment, showing one to two month declines followed by stabilization and improvement in psychological and physical health are seen in relocating older adults. Research conducted with nursing home residents may shed light on the adjustment process in individuals relocating to assisted living.

$\underline{\text { Research on Assisted Living }}$

The research conducted with residents of assisted living has focused on three major areas: satisfaction with assisted living, quality of life in assisted living facilities, and longitudinal 
Adjustment to Assisted Living 10

studies of assisted living residents. The satisfaction studies focused on organizational, environmental, and health factors impacting satisfaction among assisted living residents. The studies examining quality of life compared residents of assisted living with residents of nursing homes or community-dwelling older adults on various psychological constructs. Finally, the longitudinal studies compared assisted living residents with nursing home residents on various physical and mental health measures.

Sikorska (1999) interviewed 156 residents of 13 assisted living facilities. Information was obtained on organizational and environmental features of the facilities through interviews with the facility administrators, including an adaptation of the Multiphasic Environmental Assessment Procedure (Moos \& Lemke, 1992). Residents completed a measure of satisfaction with assisted living developed for the study. Correlational analyses were conducted for psychological well-being, functional ability, participation in the decision to relocate, and educational level. Results indicated that residents with lower education levels, greater functional ability, and who had participated in the decision to relocate were more satisfied with assisted living. Moreover, residents of smaller facilities and with more personal space were more satisfied with assisted living. Multiple regression analyses revealed that 47 percent of the variance in satisfaction was explained by these factors, with psychological well-being explaining the greatest degree of variance.

In a similar study, Mitchell and Kemp (2000) measured life and facility satisfaction among 201 residents of 55 separate assisted living facilities. Residents completed the Life Satisfaction Index-A, the Older Adult Health and Mood Questionnaire, and the Facility Satisfaction Questionnaire. In addition, they provided demographic information and information on functional ability, health status, contact with family, social activities, and completed the 
Adjustment to Assisted Living 11 Sheltered Care Environment Scale. Facility administrators completed the Resident Control Subscale of the Policy and Program Information Form measuring various aspects of control allowed residents in the facility. Overall, residents reported moderate levels of life satisfaction and moderate to high levels of facility satisfaction. However, 41 residents (20\%) attained scores classifying them as possibly depressed and 12 individuals (6\%) were classified as probably depressed. Health status was significantly related to quality of life, depression, and life and facility satisfaction with healthier individuals reporting higher quality of life, life and facility satisfaction, and lower levels of depression. Family contact and involvement in social activities were most predictive of life satisfaction in regression analyses. Mitchell and Kemp provide good information on assisted living residents but without the use of a comparison group, no conclusive statements on the impact of assisted living environment on residents can be made.

Quality of life in dementia patients residing in assisted living was assessed by GonzalesSalvador et al. (2000). Fifty-six residents of assisted living with a diagnosis of dementia were contrasted with sixty-four residents of a skilled nursing home on measures of cognition, dependency, depression, behavioral disturbance, and quality of life. Assisted living residents had significantly higher quality of life than nursing home residents. Stepwise regression analysis found quality of life to be significantly predicted by orientation, physical dependency, and use of anxiolytic medication, with greater quality of life related to better orientation, lower physical dependence, and decreased use of anxiolytic medications. These results are similar to a study by Parmalee, Katz, and Lawton (1989) that found assisted living residents to have lower rates of depression than nursing home residents. Grayson et al. (1995) compared 102 residents of retirement communities and age-segregated apartments that provided assisted living services with 351 community dwelling older adults on the Depression Adjectives Check Lists. Assisted 
Adjustment to Assisted Living 12 living residents had significantly higher levels of depression than community dwelling elders. These results promote the distinction of assisted living as a step between residing in the community and residing in a nursing home.

Two studies have compared rates of change in assisted living residents with rates of change in nursing home residents: Pruchno and Rose (2000) and Frytak et al. (2001). Pruchno and Rose followed 158 White, Jewish residents of either an assisted living facility $(\mathrm{N}=82)$ or a skilled nursing home $(\mathrm{N}=76)$ over a year. Interviews were conducted at baseline, 4, 8, and 12 months, and included formal assessments of cognition, functional status, depression, and subjective health. At baseline, and throughout the year, the assisted living residents had significantly higher functional health ratings, better self-rated health, and lower levels of depression. However, mortality and relocation rates did not differ significantly between the two groups. In other words, there was no significant main effect of facility on mortality or relocation. Pruchno and Rose found a decline in functional status in both groups related to recency of admission, with newly admitted residents experiencing greater declines than residents who had been in the facility a greater length of time. It should be noted that there was a significant difference between the groups on length of stay with all of the assisted living residents being newly admitted while only one-third of the nursing home residents had relocated in the past 3 months. Therefore, recency of relocation may have influenced the results. In a separate study, Frytak et al, followed 610 nursing home residents and 605 residents of assisted living over a year. Assessments of functional status, health, psychological well-being, pain and discomfort, cognitive status, and social interaction were conducted at baseline, 6, and 12 months. Assisted living facility residents were less impaired at baseline but changes in health, pain and discomfort, and psychological well-being were similar in both groups. Moreover, length of stay did not 
Adjustment to Assisted Living 13

affect the change rates over time. These two studies suggest significant differences in the severity of health and adjustment variables between assisted living and nursing home residents; however, patterns of physical and mental decline appear similar across both groups.

The research on assisted living discussed previously demonstrates the similarity of nursing home and assisted living residents, particularly in patterns of adjustment and decline over time. Individuals enter assisted living at a higher level of functioning but do not experience fewer declines over time because of residing in an assisted living facility. However, residents of assisted living report greater quality of life and life satisfaction than do residents of nursing homes. In addition, assisted living residents report greater levels of depression and lower levels of life satisfaction than residents living in the community. Comparisons of assisted living and nursing home residents with community dwelling older adults indicate the unique aspects of each group and place the assisted living population on a continuum between living independently and residing in a skilled nursing home.

As evidenced by the above reviews, the psychological and medical consequences for individuals following relocation are still unclear (Baglioni, 1989). The contradictory findings throughout the relocation literature suggest that factors related to relocation (e.g., health), not just the event of relocating, may be involved in an individual's adjustment following relocation. In a comprehensive review of the relocation literature, Kasl and Rosenfield (1980) divided moves made by the elderly along several variables, including improvements in housing and whether the move was made voluntarily. They found modest benefits (e.g., increased social activity and self-evaluation of current life circumstances) of relocation to improved housing when the move was voluntary. Conversely, involuntary moves were associated with more hospital and nursing home admissions, poorer self-ratings of health, and greater reports of 
Adjustment to Assisted Living 14 anxiety and depression, even when the move involved improved housing for the individual. Degree of environmental change has also been found to be important, with radical changes (i.e., a significant change in social and physical environments) being detrimental to the individual (Grant et al., 1992). Because moves from private residences into senior care homes involve radical environmental changes, it is likely that they are more detrimental than a move between private residences. Institutionalization may be particularly stressful to older individuals who feel that they have no control over relocation.

The types of relocation (e.g., voluntary vs. involuntary, degree of change) have different effects on older adults. Voluntary relocations with little change in the environment create positive effects (e.g., improved health) or mitigate negative effects and involuntary, radical moves involving a drastic change in environment are often associated with detrimental effects (e.g., poorer health). Institutionalization, specifically relocation from a private residence to a nursing home, is typically involuntary and radical, and occurs with individuals who are physically and mentally least able to adjust. Therefore, the effects of voluntarily choosing to move or control over relocation may be particularly relevant to this population of movers. Given the importance of control on adjustment, it is important to review the literature on control in older adults.

\section{Control in Older Adults}

Prior to the 1960 's, self-rated physical and functional health were widely believed to be the main predictors of psychological well-being. More recent research, however, has demonstrated the importance of various aspects of control in predicting well-being (Bowsher \& Gerlach, 1990). Research on relocation has suggested a positive effect of control on later adjustment following a move (Blenkner, 1967; Langer \& Rodin, 1976). Control is defined as the 
ability to manipulate some aspect of the environment (Schulz \& Brenner, 1977). Researchers have divided control into several categories based on what aspect of the environment is being measured, such as behavioral and decisional control. Behavioral control involves the ability to make a response that directly influences the characteristics of an event. For example, an individual exhibiting control over when or how medication is given would have behavioral control. Decisional control involves the range of choices or options an individual has available. An individual who has three living arrangements available to him or her has more decisional control than an individual who has only one option available. The effects of control are studied by allowing individuals to manipulate a portion of their environment. In an early theoretical examination of control, Corah and Boffa (1970) presented subjects with stimuli paired with aversive consequences (a 2-second loud noise). Half the individuals were given the choice to escape the noise. Individuals given a choice did not escape more frequently than the controls, but experienced less autonomic arousal and self-reported stress than individuals not given a choice. In addition, individuals given a choice described the stimulus as less threatening than individuals not given a choice. Thus, control decreased the negative effects and evaluations of an aversive stimulus and the resultant physiological arousal, even when overt behavior did not change.

Applied research on control has demonstrated that the effect of control is highly variable (Rodin, 1986a; Wolinsky \& Stump, 1996). Some individuals require more or less control than others to avoid distress. When the amount of perceived control is congruent with one's expectations regarding control (e.g., desirability of control), negative effects are likely to be diminished (Rodin). For example, an individual who desires and expects control in a specific situation (e.g., relocation), experiences less distress when they have control in that situation. However, an individual who neither desires nor expects control experiences more stress when in 
control. Shapiro, Schwartz, and Astin (1996) proposed that such mismatches in desired and actual control are detrimental to individuals. Specifically, individuals who have control and are unable to use it effectively due to behavioral or cognitive deficits or a lack of desire for control experience negative consequences from control (e.g., psychological or physical discomfort or distress). This differential effect of control is directly applicable to relocation decisions. However, research with older adults has not attempted to distinguish individuals who do and do not desire control.

In the relocation literature, the degree to which a move is voluntary is often equated with control. Individuals who enter an institution voluntarily are seen as exhibiting more control than individuals who enter involuntarily (Kasl \& Rosenfield, 1980; Schulz \& Brenner, 1977). However, while voluntariness and control are related, they are not synonymous. An individual may be willing to do something he or she would not choose to do. Individuals can relocate voluntarily without having control over that decision. For example, a family member may make the decision about entry into an assisted living facility and the older adult may simply go along when he or she would prefer an alternative solution or has no alternate choice available. On the other hand, individuals who enter an institution involuntarily are likely to have little control. Studies have found that individuals who relocated voluntarily experienced less anxiety (Thomasma, Yeaworth \& McCabe, 1990), increased physical and cognitive functioning (Bourestom, 1984; Pablo, 1977), and fewer problems (Bourestom \& Pastalan, 1981) than involuntarily relocated individuals. Moreover, Danermark and Ekström (1990) found lower mortality rates among individuals who were relocated voluntarily. In addition, positive feelings about entry into a nursing home, preference to remain in the facility, and current control over the environment were related to life satisfaction, morale, and satisfaction with treatment (Harel \& 
Noelker, 1982). Schulz and Brenner reviewed the findings on control and relocation and suggested that the more choice an individual has about being relocated, the fewer negative effects relocation will have on the individual. However, the desirability of control, as mentioned earlier, should be considered when interpreting these findings.

Several studies and reviews have demonstrated decreased experience of control with increased age, regardless of living situation (Mirowsky, 1995; Rodin, 1986a; Wolinsky \& Stump, 1996). There is a strong negative relation between actual control and age even when physical impairment, socioeconomic status, and education are controlled in analyses (Wolinsky \& Stump). However, several studies found that older adults report more or the same amount of control as younger adults (Bradley \& Webb, 1976; Lachman, 1986) and evidence suggests that the perception of control does not necessarily decline with age (Rodin, 1986a). One explanation for this discrepancy between actual and perceived control may be the fundamental attribution error (White \& Janson, 1986); individuals tend to attribute ineffective behavior to aspects of the environment and effective behavior to their behavior. In other words, older adults may perceive the environment as causing problems, not the lack of personal control. Therefore, although actual control may decline, older adults may not perceive less control as they age, potentially creating a discrepancy between perception of control and reality. Finally, perhaps perception of control is not related to the number of options available. Thus, as the number of options declines, perceived control over those options remains stable. Older adults may not view the number of choices as relevant to their degree of control. Several explanations for the potential negative relation between control and age have been proposed, including increased interaction with the medical establishment, which fosters dependence, increased assistance from others even when the assistance is not needed, deteriorating health, and increased experience of negative life 
Adjustment to Assisted Living 18

events (e.g., death of loved ones) leading to decreased social contacts (Rodin, 1986a; Wolinsky \& Stump). All of these factors may be related to less perceived and actual control among older adults. Although it has not been clearly demonstrated that all types of control decline with age, the potential relation between age and control should not be disregarded in future research on control.

Due to the apparent influence of age on both actual and perceived control, much research has been conducted on control and health in older adults (see Rodin, 1986a for a review). Rodin (1986a) concluded that restrictions on actual control are detrimental to the health of individuals and that this relation increases with age. Comparable conclusions with regard to psychological well-being were made by Bowsher and Gerlach (1990) following an examination of 302 residents of nursing homes. A stepwise multiple regression analysis revealed that actual control explained 19 percent of the variance in psychological well-being. Moreover, a lack of control is related to increased mental health problems and poorer self-perceptions of physical health in older adults (Rodin, 1986a). Smits, Deeg, and Bosscher (1995) found that well-being measures (i.e., measures designed to assess quality of life and health) were related to measures of control among 119 community dwelling older adults. Finally, in a study that was not conducted exclusively with older adults, Rodin (1986b) found increased actual control related to decreased morbidity in several physical conditions (e.g., cancer, heart disease). Since older adults may experience less actual control than younger adults (Rodin, 1986a), they may experience more of the negative effects of decreased control.

In an examination of the relation between actual control and mortality in older adults, Blenkner (1967) randomly assigned older adults to one of three social and medical service groups. The groups were given different levels of services: low service (i.e., education and 
referrals only), moderate service (moderate levels of in-home services), and high service

(intensive social and medical services). The groups had similar demographic and health variables upon initial examination. Individuals who received the highest degree of service experienced less control than low service groups. After six months, mortality rates were different between the three groups. The group receiving the highest degree of care had the greatest mortality rate, while those receiving the least amount of care had the lowest mortality rate. Other studies have also found higher mortality rates among individuals with low degrees of control (e.g., Langer \& Rodin, 1976; Schulz, 1976). It is important to note that some studies have failed to replicate the relation between control and mortality (e.g., Schulz \& Hanusa, 1978), although the positive relation between control and health supports this relation. In addition, a mismatch between actual and desired control (e.g., individuals who do not desire control are required to use control) is related to increased physical symptoms (Shapiro et al., 1996) and possibly a higher risk of death. The research conducted in nursing homes has shown both positive and negative attributes of control.

Most research on control suggests that control is positively related to physical and mental health. Individuals residing in an environment that permitted control reported greater life satisfaction than those living in an environment permitting little or no personal control (Wolk \& Telleen, 1976). Interventions designed to increase control in nursing home patients have led to increased physical and psychological health, memory ability, self-reported happiness, activity levels, and reported satisfaction (Blenkner, 1967; Bowsher \& Gerlach, 1990; Clark, 1988; Langer \& Rodin, 1976; Rodin, 1986a). For example, nursing home residents who were given control over visiting patterns experienced increased psychological and physical well-being (Arling, Harkins, \& Capitman, 1986). Moreover, increased control led to greater social 
Adjustment to Assisted Living 20 interaction and self-reported happiness. In addition, Perlmuter, Monty, and Chan (1986) reported that perceived control was positively associated with motivation and problem solving ability, and negatively associated with stress. Although these studies found positive effects of control, it is important to note that individual benefits of control varied among older adults and some individuals may have experienced no gains or a decline when given control. Overall, however, the perception of control appears to generally benefit older adults.

In addition to the positive effects of control, several studies have examined the negative effects of a lack of control. Institutionalization has a strong, negative effect on personal control even when impairment level, negative life events, social contact, and other factors are controlled (Arling et al., 1986). Marlowe (1974: as cited in Noelker and Harel, 1978) found that involuntarily relocated residents had higher mortality rates in comparison to base rates of mortality. Restrictions in control were related to decreased physical health in these older adults. In addition, Rodin (1986a) reported that the repeated frustration of not being in control might cause physiological damage in older adults (e.g., ulcers). Rodin (1986a) also found the loss of control among older adults to be more aversive than continual lack of control and may increase mortality (Schultz \& Hanusa, 1978). Finally, Perlmuter et al. (1986) found a negative relation between control and frustration. With the prevalence of interventions designed to increase control in nursing homes, it is important to guard against this potential negative effect following the cessation of a control-enhancing intervention.

The previous discussion provides strong evidence of the positive effects of having control and the negative effects of a lack of control. However, having control is not always beneficial. Bowsher and Gerlach (1990) found negative effects in older adults who had control but lacked the competence to effectively utilize it. For example, an older woman who has always relied on 
Adjustment to Assisted Living 21

her family to make important decisions may experience distress if required to make a decision on her future living arrangement. Shapiro et al. (1996) found that when a mismatch occurs between desired and actual control, individuals are likely to experience decreased health and increased anxiety and self-blame. Control may also be detrimental even when it is desired. Rodin (1986a) found that control requires an individual's time, effort, and resources and places the individual at risk of failure. Moreover, there are potential physical costs (e.g., fatigue) to exerting control (Rodin, 1986a). Therefore, having control may not always be beneficial to older adults.

\section{Decisional Control Over Relocation in Older Adults}

Rodin (1986a) postulated that response to relocation was largely determined by an individual's perceived ability to control and predict the move and the degree of control pre- and post-relocation. The impact of control post-relocation has been discussed and control over relocation is often called decisional control. Decisional control is simply the opportunity to make choices (Pohl \& Fuller, 1980). In the relocation literature, it involves the opportunity to make the decision whether to relocate, as well as when and where to relocate. In the research on relocation, decisional control has been examined in terms of voluntary vs. involuntary relocation or the degree of willingness to move (Danermark \& Ekström, 1990). It is important to note that these terms are not synonymous, as discussed previously. Individuals can voluntarily or willingly enter a nursing home even if they did not make or influence the decision to relocate. Also the degree of control over the decision may vary on where to move but not on when to move.

Despite the apparent benefits of control, the majority of older adults are not involved in the decision to relocate to a nursing home (Coulton, Dunkle, Chow, Haug, \& Vielhaber, 1988; Coulton et al., 1982; Nay, 1995). A review of the literature on decisional control reveals several factors that affect involvement in decision-making. Coulton et al. (1988) found several factors 
Adjustment to Assisted Living 22 influenced participation in discharge planning from hospitals: time allowed to make the decision, restriction of choices for future living environments, degree to which decisional outcomes are final, family support, and control over the decision. Patients who were partially or fully involved in discharge planning reported higher degrees of satisfaction with discharge plans than individuals not involved in discharge planning. The ability to participate in planning was related to level of cognitive or physical impairment, information available, perceived freedom of choice, time allowed to make a decision, degree of hope, family power structure, commonality of family goals with the patient's goals, physicians' opinions, social support, and patients' assertiveness (Coulton et al., 1982). Although these factors were related to participation in planning, none were analyzed in relation to satisfaction with discharge plans or actual decisional control. Many factors influence decisional control and thus adjustment to the nursing home environment.

In a recent review of studies on decisional control and adjustment, Drozdick (unpublished), concluded there is little empirically valid research on decisional control and the adjustment of community-dwelling older adults to relocation. Although several studies have demonstrated some relation between decisional control and adjustment, the validity and reliability of the majority of results are questionable. Poor research methodology (e.g., mixed or poorly defined sample groups, retrospective measures, use of raw change scores, use of psychometrically unproven instruments) in most of the studies limited the interpretation and generalizability of the results. However, there does appear to be some relation between decisional control and adjustment, although the strength and direction of the relation is unclear. In addition, studies have provided supportive evidence that the first month is the most difficult time for adjustment among individuals relocating to nursing homes (Davidson \& O'Connor, 1990; Reinardy, 1992, 1995). Studies conducted by Pohl and Fuller (1980) and Pino, Rosica, and 
Adjustment to Assisted Living 23

Carter (1978) offer the best evidence that involuntary relocation or a lack of decisional control over relocation are related to poorer adjustment following relocation. The reviewed research suggested the importance of decisional control on adjustment but failed to answer the fundamental questions of whether or how decisional control influences adjustment in this population.

\section{Statement of Problem}

Only a small portion of the research on relocation into long-term care facilities has focused on individuals relocating to assisted living facilities, and less has focused on adjustment among relocated individuals. Moreover, none of the research on assisted living has addressed the short- and long-term adjustment phases seen in the relocation literature. In addition, the importance of decisional and environmental control for psychological well-being in older adults is likely an underexamined factor in adjustment. The study conducted by Mitchell and Kemp (2000) offers some insight into the role of control in life satisfaction in assisted living facilities but fails to address the role of control in other facets of adjustment. A more comprehensive examination of the adjustment process among residents of assisted living and the relation of control to adjustment is needed. It is important to examine this growing population of older adults, as they are likely to experience a significant change in lifestyle and living environment post-relocation, similar to that seen in nursing home relocation. With approximately 5 percent of older adults residing in senior-care facilities at any point in time (Maddox, 2001) and a growing percentage of these older adults utilizing assisted living instead of nursing home services, it is essential that more information on the adjustment to relocation to assisted living be obtained.

The current study incorporates and expands previous research to gain a more thorough understanding of adjustment to relocation into assisted living facilities. Previous studies have 
used various definitions of assisted living, from retirement communities offering limited personal care services to formal assisted living facilities. As the assisted living industry has grown over the past decade, a more formal definition of assisted living has been put forth. In a national study of the assisted living industry, Manard and Cameron (1997) defined assisted living as a "type of care that combines housing and services in a residential environment and that strives to maximize the individual functioning and autonomy of residents." The average assisted living facility houses 40 residents and provides 24 -hour supervision, three meals a day, and a range of individual services for residents, such as assistance with bathing, housekeeping, or transportation (NCAL, 1998). The current study utilizes a homogenous sample of facilities meeting the previous definitions and descriptions. All assisted living participants resided in a facility housing at least 20 residents which provided individual care, including meals, 24-hour supervision, and individual services for residents, and was marketed as an assisted living facility stressing resident autonomy and functioning.

Earlier analyses of adjustment following relocation have found the first 6-8 weeks following relocation as the most difficult in terms of negative impact on health and psychological well-being (Kasl \& Rosenfield, 1980; Mikhail, 1992; Tobin \& Leiberman, 1976). This short-term distress appears to diminish by three months (Grant et al., 1992; Tobin \& Leiberman, 1976). In order to capture adjustment at both the short-term and long-term phases, residents relocating into assisted living facilities were assessed at baseline (1-2 weeks postrelocation), 1 month, and 3 months post-relocation. The one-month assessment captured shortterm adjustment and the three-month assessment addressed long-term adjustment.

Previous studies comparing assisted living with other groups have typically used nursing home residents. Only Grayson et al. (1995) compared the residents of assisted living with 
Adjustment to Assisted Living 25 community residents. However, the assisted living sample consisted of residents in a retirement community using assisted living services, not residents of an assisted living facility. While a control group comprised of community residents is useful to study the impact of relocation to the facility, the community sample should closely resemble assisted living residents in order to minimize the influence of extraneous variables (e.g., functional health) on subsequent analyses. The current study reduced group variability by utilizing a control group of community dwelling older adults similar to the typical assisted living resident. All community adults were mobile, over the age of 60, and required assistance with at least one instrumental activity of daily living. Item analyses revealed no consistent significant differences between groups on the type of IADL impairment reported across the 3 time periods.

To address the issue of poorly designed or developed measures of adjustment variables (e.g., health, affect, coping style) seen in previous studies, measures validated with older adult samples were used whenever possible. In addition, several variables known to affect adjustment were examined in relation to adjustment (e.g., health, control, social support). The current study also examined two new aspects of adjustment not previously examined in the relocation literature (anxiety and the broader concept of affect that includes some aspects of anxiety), and examined environmental control in relation to adjustment. Anxiety and affect are both related to medical and psychological morbidity, as well as stressful events (for brief reviews see Fisher \& Noll, 1996 and Schultz, O’Brien \& Tompkins, 1994, respectively). Including them as variables allowed for a more comprehensive examination of adjustment and its relation to control.

The following hypotheses were proposed based on previous literature: (a) Older adults entering assisted living facilities will demonstrate the short- and long-term adjustment phases seen in the literature on relocation to nursing homes (e.g., greater depression and anxiety, lower 
Adjustment to Assisted Living 26

life satisfaction at 1 month than at 3 months), (b) older adults relocating to assisted living will endorse more symptoms of depression, anxiety, and negative affect and report lower life satisfaction than community residents at all 3 assessments, (c) assisted living residents will have a greater difference between desired and actual environmental control than residents remaining in the community, (d) residents of assisted living will show greater declines in health, functional status, life satisfaction, and affect and greater increases in depression and anxiety over the 3 assessments than residents remaining in the community, (e) less decisional control among the assisted living sample and environmental control in both groups will be related to poorer adjustment at all 3 assessments (e.g., endorse more symptoms of depression, anxiety, and negative affect, and report lower life satisfaction), and (f) decisional control among the assisted living sample and environmental control in both groups will be related to health status across all 3 assessments (i.e., residents with better health will report greater decisional and environmental control).

\section{Method}

\section{$\underline{\text { Participants }}$}

Two groups of individuals were recruited for participation, one from assisted living residences and one from the community. All assisted living facilities were located in the Southern United States and affiliated with corporations specializing in senior healthcare and housing. All six facilities offered 24-hour non-medical supervision, assistance with personal and medical care, and provided semi-private and private apartments for residents. Participating assisted living facilities were contacted every two weeks regarding new residents and scheduled admissions. Fifty-seven community dwelling older adults, age 60 and older, who relocated to an assisted living facility, were recruited and asked to participate. Eighteen qualified and chose to 
participate for an overall participation rate of 32 percent. All residents were relocating from community residences less than 100 miles from the assisted living facility. See Table 2 for the percent of residents excluded for various reasons. Twenty-five community dwelling older adults responded to advertisements placed through social service organizations, newspapers, and local churches. To ensure an appropriate comparison group of community-dwelling older adults, community-dwelling participants had to require at least some assistance with one or more instrumental activities of daily living. Nineteen individuals met inclusion criteria and completed the study for an inclusion rate of 76 percent. Six individuals reported no functional impairment in instrumental activities of daily living and were excluded. Each participant was paid 25 dollars for participating, five dollars for the initial session and ten dollars for each follow-up session. Six participants chose to have their payments donated to a charity in lieu of direct payment.

Given the high rate of cognitive impairment in assisted living residents, all assisted living participants were required to obtain a score of at least 15 on the Mini Mental State Examination (MMSE; Folstein, Folstein, \& McHugh, 1975). This has been suggested as the cutoff point to ensure the validity of self-report data in older adults (Edelstein, Kalish, Drozdick, \& McKee, 1999) and has been used in research with assisted living residents (Pruchno \& Rose, 2000). The MMSE criterion was not intended to rule out individuals with any cognitive impairment, but rather to limit the variability in test scores due to diffuse cognitive impairment or inability to complete the assessment upon entrance to the study. Although individuals with focal deficits might have passed the screen, the MMSE was intended as a brief screening measure and limited the number of participants with severe, diffuse cognitive impairment. Cognitive status was assessed at each subsequent interview with the cutoff scores described above on the MMSE. No participants failed to meet the cutoff score at either follow up assessment. 
$\underline{\text { Measures }}$

Adjustment to Assisted Living 28

Demographic information was collected on age, gender, race, marital status, and current living arrangement (e.g., personal home, home of a relative, assisted living facility). Information was also collected on medical concerns and use of medications. For relocating individuals, information on perceived personal and family involvement in the decision-making process was gathered. This included both a Likert-scale questionnaire and open-ended questions on the individual's and family's involvement in the decision to relocate. Assisted living residents provided the reasons for relocating to an assisted living facility and community residents stated conditions under which they would consider moving into an assisted living community. See Appendix A for a copy of the demographic questionnaire. Appendix B contains a copy of the questionnaire on decisional involvement. In addition, assisted living residents were administered a measure of perceived decisional control. Finally, on initial and follow-up visits, measures of various aspects of adjustment, health status, and control were obtained. No direct standard measure of adjustment has been developed. Therefore, standard measures of various aspects of adjustment (e.g., depression, life satisfaction) were used. Specifically, a measure of self-rated health, the Instrumental Activities of Daily Living Scale (Lawton \& Brody, 1969), the Geriatric Depression Scale-15 (Sheikh and Yesavage, 1986), the Life Satisfaction Index Form Z (Wood, Wylie, \& Sheafor, 1969), the Profile of Mood States-Short Form (Shacham, 1983), the Beck Anxiety Inventory (Beck, Epstein, Brown, \& Steer, 1988), the Short Form of the Desired Control Scale (Reid \& Zeigler, 1981), and the Norbeck Social Support Questionnaire (Norbeck, Lindsey, \& Carreri, 1981) were administered.

Perceived decisional control or involvement in the decision to relocate was assessed using a four-item questionnaire assessing perceived control over the decision to move to the 
Adjustment to Assisted Living 29 nursing home. This measure of perceived control was developed by Davidson \& O'Connor (1990) and demonstrated good internal consistency $(\alpha=.85)$. See Appendix $C$ for a copy of this measure. The overall score was used in the analyses with higher scores representing greater involvement in the decision.

Health status was assessed using a single item question on global self-rated health. Individuals rated their health on a four-point scale from "excellent" to "poor." Lawton and Lawrence (1994) report the use of a single item as a good option for older adults when physical health is not the main focus of research. Single-item measures have been correlated with health behaviors (e.g., smoking, obesity) (George, 2001), assessment of health by physicians (Maddox \& Douglass, 1973), and are superior to medical indices in predicting mortality (Idler \& Kasl, 1991; Mossey \& Shapiro, 1982). In addition, studies on adjustment frequently measure health in a similar manner (e.g., Konnert \& Crowhurst, 1996; Pohl \& Fuller, 1980; Sherwood, Glassman, Sherwood, \& Morris, 1974). See Appendix D for a copy of this item. Overall score was used in the analyses. Higher scores represent poorer health (e.g., a score of 4 was "poor").

Lawton and Brody's (1969) Instrumental Activities of Daily Living Scale (IADLS) was used to assess functional status. It is completed based on interview and observation and assesses an individuals ability to independently complete 8 areas of daily living: using the telephone, traveling, shopping, preparing meals, doing housework, doing laundry, taking medications, and managing money. Individuals are rated on a 3-point scale from 0 (unable to complete) to 2 (needs no assistance) on each activity. Scores range from 0 (complete impairment) to 16 (completely independent). Total score was used in the analyses.

The Geriatric Depression Scale-15 (GDS15; Sheikh and Yesavage, 1986) is a short form of the Geriatric Depression Scale and consists of 15 yes/no items designed to detect depression 
Adjustment to Assisted Living 30 in older adults. A copy is provided in Appendix E. Respondents report depressive symptoms over the past week. Parmalee, Katz, and Lawton (1989) found the GDS to be a valid and appropriate measure of depression for cognitively impaired older adults. Moreover, Rose (2002) found good internal and external validity and test-retest reliability for the GDS with an assisted living sample. The GDS15 demonstrated good internal consistency (Cronbach alpha $=0.80$ ), and high external validity with the original GDS $(r=0.84, p<.001)$ (Sheikh \& Yesavage, 1989) and the Beck Depression Inventory $(r=0.91, p<.01)$ (Olin, Schneider, Eaton, Zemansky, \& Pollock, 1992). The overall score was used in data analyses with higher scores representing greater endorsement of depressive symptoms.

Overall life satisfaction was measured with the Life Satisfaction Index Form Z (LSI-Z: Wood et al., 1969). This measure was developed on older adults and consists of 13 statements related to life satisfaction. Individuals indicate whether they agree or disagree with statements related to various aspects of life satisfaction (i.e., mood tone, goal congruence, self-concept, apathy). Higher scores indicate greater satisfaction. The index produced a split-half reliability of 0.79 and correlated moderately with two other life satisfaction scales, the Life Satisfaction Index Form A and the Life Satisfaction Ratings ( $r=0.57$ and 0.79 , respectively) (Neugarten, Havinghurst, \& Tobin, 1961).

Affect was assessed using the short version of the Profile of Mood States (POMS-SF: Shacham, 1983). The short version of the POMS is a 37-item list of adjectives pertaining to one of six mood states. The individual rates his or her mood over the past week on a five-point scale. Internal consistency was high in both healthy adults $(r=.87)$ and medically ill adults $(r=.90)$ (Curran, Andrykowski, \& Studts, 1995). It is sensitive to change and was developed and normed on a sample that included individuals over the age of 60 (National Center for Cost Containment, 
Adjustment to Assisted Living 31 1996). Overall score was used in the analyses with higher scores representative of greater negative affect.

The Beck Anxiety Inventory (BAI; Beck et al., 1988) was used to assess anxiety symptoms. The BAI is a 21-item scale on which individuals rate their anxiety symptoms on fourpoint scales. It has demonstrated good reliability and validity with older psychiatric outpatients and community dwellers (Kabacoff, Segal, Hersen, \& Van Hasselt, 1997) and high internal consistency with older medical inpatients (Wetherell \& Arean, 1997). Studies on the sensitivity and specificity information on the BAI found that the overall score is helpful in detecting an anxiety order (Kabacoff et al., 1997). Overall score was used in the analyses with higher scores reflecting higher levels of anxiety symptom endorsement.

The Desired Control Scale-Short Form (Reid \& Zeigler, 1981) was used to assess perception of control over the environment. It was developed with older adults and consists of 32 items divided into two sixteen-item scales. The first scale assesses the desirability of certain situations (e.g., "How important is it to you that you maintain your health?") and individuals respond to the questions on a five-point scale, ranging from very desirable to very undesirable. The second scale assesses control over the situations (e.g., "Maintaining my level of health strongly depends on my own efforts.") and elicits responses ranging from strongly agree to strongly disagree. The presence of two separate scales was not upheld in a factor analysis, suggesting the measure is a unidimensional measure of the experience of control. The measure demonstrated good internal consistency (Cronbach $\alpha=.73$ for Desired Control; Cronbach $\alpha=$ .69 for Expected Control) and predictive validity for health and life satisfaction ( $\mathrm{r}$ value ranges from 0.23 and $0.44, \mathrm{p}<.001$ ) (Lefcourt, 1991; Reid \& Zeigler, 1981). Three scores are available: Desired Control, Expectancy of Control, and a total score. An overall score is obtained by 
summing the products of the parallel items on the separate desire and expectancy scales, providing a weighted score. The computation of the total score relies on the two scales being relatively independent. However, within the current study, the correlations between the desirability and expectancy scales were significant at all three time points $(r=.53, p=.001$; $r=.46, p=.004 ; r=.62, p<.001$, respectively). It is likely that the item correlations vary as well allowing some item pairs to disproportionately contribute to the total score (see Reid and Zeigler for a full discussion). Therefore, only the desirability and expectancy scales scores were used in the analyses. However, given the factor analysis results, differences between the two scales should be interpreted with caution.

Finally, social support was assessed using the Norbeck Social Support Questionnaire (NSSQ: Norbeck et al., 1981). Individuals list up to 24 members of their social network and then answer 9 questions assessing which members would provide different types of support (e.g., affect, long-term aid). The measure provides three factor scores: loss, functional social support, and strength of the social support network. Newsom, Bookwala, and Schulz (1997) reported that the NSSQ has been used successfully with nursing home residents. Moderate to high internal consistency ( $\alpha=0.97$ for functional social support and $\alpha=.72$ for network strength) and high test-retest reliability $(r=.85-.92)$ were found in a nursing home population (Rook, 1994). Higher scores on the functional and network scales represent greater social support while higher scores on the loss scale represent lower levels of support due to loss. Functional social support and network strength scores were used in the analyses.

Procedure

Participants were contacted directly to set up an initial meeting time. The initial meeting for all residents of assisted living occurred within two weeks following entry into the assisted 
Adjustment to Assisted Living 33

living facility $(X=5.56, S D=3.33)$. Data collection took place in the assisted living facility. Informed consent was obtained prior to any information being gathered and the Mini Mental Status Examination was given to determine eligibility. If appropriate, the self-report measures were administered to the participant. Due to difficulty completing the questionnaires appropriately, many assisted living residents were administered the questions verbally. The majority ( $n=15$ ) of community dwelling participants were asked to complete the self-report measures and returned them upon completion. Any problems with data completion were addressed either immediately or with follow-up interviews within three days of initial completion of the questionnaires.

Information was collected on demographics, health and medical status, and the decisional process around relocation for the assisted living residents. In addition, a variety of psychological tests were administered. These included a measure of self-rated health, Instrumental Activities of Daily Living Scale, Geriatric Depression Scale 15, Beck Anxiety Inventory, short form of the Desired Control Scale, Life Satisfaction Inventory-Form Z and Profile of Mood States-Short Form. Finally, at the end of the assessment, participants were paid five dollars.

At both 1 month and 3 months following entry into the study, participants were contacted for a follow-up interview. All assessments were collected within one week of when they were due, with the exception of one resident of assisted living who was hospitalized at the time of her second assessment. The mean time from the due date was 5.78 days $(S D=4.67)$ for assisted living residents and 4.26 days $(S D=2.54)$ for community dwelling participants at time 2 , and 4.25 days $(S D=2.46)$ for assisted living and 3.84 days $(S D=1.83)$ for community residents at time 3. These two follow-up assessments captured information on both short- and long-term adjustment, respectively. The standardized instruments were readministered at each follow-up 
assessment. Participants were paid ten dollars for each follow-up assessment.

Participants had the right to withdraw from the study at any time but were only paid for sessions that they began. Two assisted living residents did not complete the third assessment due to either death $(N=1)$ or relocation $(N=1)$. See Table 3 for the number of participants in each group at each time interval.

\section{$\underline{\text { Data Analysis }}$}

To test the first hypothesis, that older adults entering assisted living would demonstrate the short- and long-term adjustment phases seen in the nursing home relocation literature (e.g., greater depression and anxiety, lower levels of life satisfaction, functional and physical health at 1 month than at 3 months), several repeated measures ANOVA's were used. Dependent variables included scores obtained on the measures of functional and physical health, GDS15, LSI-Z, POMS-SF, and BAI at time1, time 2, and time 3. Six separate 1 x 3 [group (assisted living) x time(time 1, time 2, time 3)] repeated measures ANOVA's were conducted, one for each adjustment variable (i.e., scores on IADLS, health, GDS15, LSI-Z, POMS-SF, and BAI). It was expected that time would have a significant impact on scores on the adjustment variables, with scores significantly different at time 2 than at time 1 or time 3 . Specifically, the following outcomes were expected: relocating individuals would exhibit greater scores on the selfperceived health scale, GDS15, POMS-SF, and BAI at Time 2 than at either Time 1 or Time 3, and relocating individuals would exhibit lower scores on the IADLS and the LSI-Z at Time 2 than at either Time 1 or Time 3. Similar analyses were conducted on the community residents, but it was expected that there would be no significant differences on scores due to time.

The second group of hypotheses, that relocating individuals would demonstrate poorer adjustment than individuals remaining in the community at all three assessments, was assessed 
with several ANCOVA's. Three separate 2 x 1 [group (assisted living, community) x time] ANCOVA's (one for each assessment) were conducted on each adjustment variable to analyze the difference between groups on measures of adjustment at all three time periods. Social support has been found to influence adjustment (Antonucci, 1990; Burman \& Margolin, 1992) and was used as a covariate to determine the degree to which relocation alone affects adjustment. Specifically, the following outcomes were expected: relocating individuals will exhibit significantly higher scores on the self-perceived health scale, GDS15, POMS-SF, and BAI at all three times than individuals remaining in the community, and relocating individuals will exhibit significantly lower scores on the IADLS and LSI-Z at all three assessments than individuals remaining in the community.

The groups were compared on environmental control at all three assessment times to test the hypothesis that older adults relocating to assisted living would have a greater discrepancy between desired and actual control than individuals remaining in the community. The discrepancy was computed by summing the values of the differences between scores on the linked items on the scale (i.e., items from the desired and expectancy scales addressing the same situation). Since it was not expected that time would have an independent affect on the analyses, three separate 2 x 1 [group (assisted living, community) x time] ANCOVA's (one for each assessment) were used to assess the effect of residence on environmental control at the three points in time. Again, social support was used as the covariate. It was expected that individuals residing in the community would exhibit less disparity, as measured on the Desired Control Scale-Short Form, between actual (expected) and desired environmental control at all three points in time than individuals residing in assisted living facilities.

The fourth hypothesis, that assisted living residents would demonstrate greater declines 
Adjustment to Assisted Living 36 in health, functional status, and life satisfaction, and greater increases in depression, negative affect, and anxiety over the 3 month period than community residents, was addressed using three separate 2 x 1 [group (assisted living, community) x adjustment period (time 1 to time 2; time 1 to time 3; time 2 to time 3)] ANCOVA's (one for each time period) utilizing change scores on self-perceived health, IADLS, GDS15, LSI-Z, POMS-SF, and BAI to assess the affect of relocation into assisted living on short and long-term adjustment variables. It was expected that individuals in the community would exhibit less change on self-reported health, IADLS, GDS15, LSI-Z, POMS-SF, and BAI scores over both periods than individuals relocating to assisted living.

Two correlational analyses were conducted to test the fifth hypothesis, that less decisional control in relocating individuals and environmental control in both groups would be related to adjustment (GDS15, LSI-Z, POMS-SF, and BAI scores). To test the relation between decisional control and adjustment, four (one each for GDS15, LSI-Z, POMS-SF, and BAI scores) bivariate correlational analyses between perceived decisional control and scores at time 1, time 2, time 3 were conducted within the assisted living group. Additionally, four (one each for GDS15, LSI-Z, POMS-SF, and BAI) bivariate correlational analyses between both DCS-SF desirability and DCS-SF expectancy and scores at time 1, time 2, time 3 were conducted within the entire sample to determine the degree of the hypothesized relation between environmental control and change scores related to adjustment variables. It was expected that as decisional control increased, scores on the GDS15, POMS-SF, and BAI would decrease and scores on the LSI-Z would increase. In other words, decisional control would be negatively related to scores on the GDS15, POMS-SF, and BAI, and positively related to scores on the LSI-Z. Also, it was expected that within both relocating and community-dwelling individuals, as environmental 
Adjustment to Assisted Living 37 control increases, scores on the GDS15, POMS-SF, and BAI would decrease and scores on the LSI-Z would increase. In other words, environmental control would be negatively related to scores on the GDS15, POMS-SF, and BAI and positively related to LSI-Z score.

Finally, three (one for each time period) bivariate correlational analyses between perceived control and both health and IADLS were conducted on the assisted living sample to determine the degree and direction of the hypothesized relation between decisional control and scores on the IADLS and self-perceived health measure at each assessment. Further, three (one at each time period) bivariate correlational analyses between both IADLS and health score and both measures of control (i.e., DCS-SF desirability, DCS-SF expectancy) were conducted within the entire sample to determine the degree and direction of the hypothesized relation between environmental control and scores on the IADLS and self-perceived health measure. Specifically, it was expected that as decisional and environmental control declined, self-perceived health would also decrease (score increase). Thus, health score would be negatively related to scores on the DCS-SF desirability, DCS-SF expectancy, and perceived decisional control scales. Also, it was expected that as decisional and environmental control declined, functional health would also decline (IADLS score decrease). Thus, IADLS score would be positively related to scores on the DCS-SF desirability, DCS-SF expectancy, and perceived decisional control scales.

\section{Results}

\section{Demographic and Qualitative Analyses}

Assisted living residents were older $(F=4.64, p=.04)$, more likely to live alone $\left(\chi^{2}=4.88, \alpha=.03\right)$, more likely to be white $\left(\chi^{2}=4.08, \alpha=.04\right)$, and less likely to be currently married $\left(\chi^{2}=3.98, \alpha=.05\right)$ than community residents. In addition, community residents reported greater functional support $(F=6.81, p=.01)$ and network strength $(F=9.53, p<.01)$ upon entry 
into the study. Functional support remained significant at time $2(F=5.47, p=.03)$, but this difference was not significant at time $3(F=3.96, p=.06)$. Network strength remained significant at both follow up assessments $(F=9.53, p<.01 ; F=4.80, p=.04$, respectively). The groups had similar gender composition $\left(\chi^{2}=0.83, \alpha=.36\right)$, prescription drug use rates $\left(\chi^{2}=2.00\right.$, $\alpha=.16)$, and presence of medical conditions $\left(\chi^{2}=2.00, \alpha=.16\right)$. Finally, the groups reported similar levels of loss over the past year $(F=2.38, p=.13)$ upon entry into the study. See Table 4 for an overview of the demographics for each group.

All assisted living residents completed an open-ended questionnaire on their involvement in the decision to enter an assisted living facility. Table 5 provides the percent of the assisted living sample that responded in various manners to the Decisional Control Questionnaire. Overall, $72 \%$ believed they were involved in the decision, although only $61 \%$ said they actually made the decision. Despite these findings, only $17 \%$ wished they had been more involved in the decision and $94 \%$ reported that they were willing to move into assisted living or had accepted the decision to relocate. Table 6 lists the reasons given for entry into an assisted living facility by assisted living residents. Medical problems and need for increased care were the most frequently reported reasons for relocation, but one-third of residents reported other's making the decision as a reason for relocation. Table 7 provides responses given by community residents when asked under what conditions they would consider moving into an assisted living facility. The inability to care for oneself and a lack of alternatives were the most frequent responses.

Descriptive information on all variables is provided in Table 8 by group and time period, including means, standard deviations, and ranges.

\section{Hypothesis 1: Adjustment Over Time}

Assisted living residents were expected to have significantly lower scores on the LSI-Z 
Adjustment to Assisted Living 39

and IADLS at time 2 than at either time 1 or time 3 , and significantly higher scores at time 2 on the health measure, GDS15, BAI, and POMS-SF than at either time 1 or time 3. See Table 9 for results of repeated measures ANOVA's, including power and effect sizes. No significant results were obtained in the assisted living sample.

Among the community residents, as predicted, no significant differences were found on the IADLS, health measure, GDS15, LSI-Z, POMS-SF, or BAI as a result of time. See Figure 1 for line graphs of mean scores for each adjustment variable at all three times, by group.

\section{Hypothesis 2: Group Differences on Adjustment Variables}

Assisted living residents were expected to demonstrate lower scores on the IADLS and LSI-Z than community residents at all three assessments. In addition, assisted living residents were expected to have higher scores than community residents on self-reported health, GDS15, POMS-SF, and BAI at all three time periods. Results of ANCOVA's for each variable, power, and effect sizes at each time are shown in Table 10. There were no significant differences between the groups on IADLS, self-perceived health, GDS15, POMS-SF, or BAI at any time period. However, scores on the LSI-Z at time 3 were significantly different $(F=7.38 ; p=.01)$. Community residents were significantly more satisfied with their lives than residents of assisted living at time 3. See Figure 1 for a graphical depiction of these differences.

\section{Hypothesis 3: Desired Versus Actual Control}

Older adults relocating to assisted living were expected to have greater disparity between desired and actual control than community dwelling older adults at all 3 time periods. Group means and standard deviations for the discrepancy scores, results of the separate ANCOVA's, power, and effect sizes for each time period are shown in Table 11. Higher scores represent 
Adjustment to Assisted Living 40 greater disparity. Assisted living residents showed greater differences between desired and actual control than community residents at all three time periods, with significant differences obtained at time $3(F=4.86, p=.04)$. The differences at time 1 and time 2 did not reach significance. Hypothesis 4: Physical and Psychological Changes Over Time

Assisted living residents were expected to have greater declines in health, functional health, and life satisfaction, and greater increases in depression, anxiety, and negative affect than community residents over the three time periods. Group change score means and standard deviations, results of ANCOVA's utilizing functional social support and network strength as covariates, power, and effect sizes are shown in Table 12. There were no significant differences between groups on any adjustment variable.

\section{Hypothesis 5: Control and Adjustment}

Within older adults relocating to assisted living facilities, decisional control was expected to relate to adjustment, with less involvement being related to poorer adjustment. See Table 13 for the correlations between perceived decisional control and scores on GDS15, LSI-Z, POMS$\mathrm{SF}$, and BAI at all three times. Although the direction of all correlations matched the direction that was predicted, only the score on the GDS15 at time 1 was significantly related to decisional control.

Within the entire sample, it was expected that environmental control (desired and actual) would be related to adjustment, with less control being related to poorer adjustment. Table 14 shows the correlations between the DCS-SF Desirability and Expectancy scales and the GDS15, LSI-Z, POMS-SF, and BAI scores at all three times. Although several did not reach significance, the direction of all correlations matched the predicted direction. Desired control was significantly related to the GDS15 at all three time periods, the LSI-Z and POMS-SF at time 3, 
Adjustment to Assisted Living 41 and the BAI at times 2 and 3. The correlations were modest at time 1 and time 2 and moderate at time 3. Actual (expected) control was significantly related to all of the adjustment variables at all three time periods, with the exception of the BAI at time 1 . The correlations were moderate at time 1 and time 2, and moderate to high at time 3 .

\section{Hypothesis 6: Control and Health}

Within the assisted living sample, perceived decisional control was expected to be negatively related to health and positively related to IADLS scores. Perceived decisional control was significantly negatively related to health in the assisted living sample at both time 1 and time 3. The IADLS score was positively related to perceived control, but the relation was not significant.

Within the entire sample, control was expected to be negatively related to health and positively related to functional health. The direction of the relations was confirmed, but desired control was not significantly related to either health or IADLS score at any time. Actual control was moderately significantly related to both health and IADLS score at time 1 and time 2 but not at time 3 .

\section{Discussion}

Several results were obtained that support the research hypotheses and merit greater discussion. In addition, several patterns were observed that need further clarification. The following discussion elaborates on the connection between the current findings and the results in previous research.

\section{$\underline{\text { Demographics }}$}

The different compositions of the groups in the present study reflect the demographics reported on assisted living residents (Gabrel \& Jones, 2000) and are similar to those described in 
other studies. The chance of entry into an assisted living or other restricted environment increases with age, therefore, the significant age difference observed between the two groups is an effect of the larger populations from which the separate samples were drawn. Also, entry into a nursing home or assisted living facility frequently follows the loss of a spouse or primary caregiver and other members of one's social network, creating a need for non-familial assistance. Therefore, the assisted living groups significantly smaller support network is not an unusual finding. Moreover, differences in social support likely reflect the loss of contact with family and friends often associated with relocation, frequently due to geographic distance. The greater number of Hispanic older adults in the community sample reflects the national demographics showing the majority of assisted living residents are white (Hawes, Rose, \& Phillips, 1999), potentially due to higher incomes among elderly Caucasians, allowing assisted living as a feasible economic choice. It may also demonstrate the underutilization of formal caregiving services among, greater non-spousal assistance provided to, or greater language barrier experienced by elderly Hispanic individuals (Ayalon \& Huyck, 2001; Levkoff, Levy, \& Weitzman, 1999; Navaie-Waliser, Feldman, Gould, Levine, Kuerbis, \& Donelan, 2001). Support for the language barrier hypothesis is demonstrated in the exclusion of two residents due to the inability to complete the English questionnaires. Finally, the similar physical and functional health status of the two groups is likely due to the restrictive inclusion criteria for the community group and likely limited the differences between groups attributable to health.

\section{Decisional Involvement Among Assisted Living Residents}

The moderate level of older adults reporting involvement in the decision to relocate by assisted living residents in the current study is consistent with those reported by Coulton et al. (1982) and Gabrel and Jones (2000). Although similar rates of involvement were found, very 
few residents in the current study reported the desire for greater involvement in the relocation decision or stated they were unwilling to relocate. Involvement in the relocation decision did not seem to be a key concern. Control over the decision produced more variation. Residents appear to have exerted their desired amount of control in the relocation decision. This is an interesting finding given early use of voluntariness in relocation as a measure of control. Voluntariness may be less discriminating than control among assisted living residents. The relatively high percentage of residents reporting willingness to relocate and the moderate percentage of residents reporting control reinforce the different nature of control over and willingness to move. Clearly many residents were willing to relocate even though they felt they had little control over the decision. However, the majority of residents appeared to recognize and accept the need for relocation, or at least chose to go along with other's desires, even if they did not personally choose to move.

Residents of assisted living reported increased need for assistance, medical problems, and other's desires as the main reasons for entering assisted living. Rarely did they report the complete inability to perform tasks. Only 11 percent reported that they had no other choice. In contrast, community residents reported that entry into an assisted living facility would occur only due to inability to care for themselves, drive, or maintain their home. In addition, several stated they would only move into an assisted living facility if there was a lack of alternate choices, and ten percent stated they would never enter an assisted living facility. Community residents appeared to have strong resistance to relocation to assisted living facilities, often seeing it only as a last resort. Given the similar physical health of and apparent need for assistance in the two groups, community residents may be in need of the increased care offered in assisted living facilities, but do not view assisted living as a viable choice for them. The different responses 
Adjustment to Assisted Living 44

given by residents of assisted living facilities and the community residents regarding entry into assisted living draw attention to different perceptions of the purpose of assisted living facilities.

\section{$\underline{\text { Adjustment Over Time }}$}

The finding that time did not have a significant impact on adjustment within assisted living residents was inconsistent with previous findings showing poorer adjustment at one to two months than seen at 3 months following relocation. This was surprising given the consistency and strength of this finding in previous literature. No significant differences as a result of time were seen on any of the adjustment variables. Moreover, only depression showed the predicted pattern over time. Scores on the POMS-SF and BAI were opposite the predicted pattern, showing less negative affect and anxiety at time 2 than at either time 1 or time 3 . Health may have played a role in these findings. Residents often enter an assisted living facility following a significant health decline. Staff provide medication management, meals, and appropriate supervision, potentially resulting in immediate improvements in health or stabilization of existing medical problems. Therefore, the short-term effects of relocation may be counteracted by improved health or cessation of physical decline. Although a similar positive effect of relocation could be predicted for nursing home residents, the severity of health decline is likely less severe and the degree of potential medical improvement greater among assisted living residents. Some evidence of health stabilization is provided by the lack of change in functional and self-perceived health among assisted living residents.

Assisted living residents' health scores were exactly the same from time 1 to time 2, and improved from time 2 to time 3 . IADLS scores declined less than 1 point, on average, over the three month period. Perhaps the assisted living environment fulfills a need in relocating 
individuals that other types of relocations do not (e.g., orientation planning, increased social contact, medication stabilization), thus lessening the negative effects of relocation. In addition, the emphasis within assisted living facilities on providing a homelike atmosphere and promoting resident independence may reduce the severity of change seen in the relocation literature conducted in nursing homes. However, the timing of data collection may also have played a role. The collection of time 1 data occurred immediately after entry and may not have captured premove distress. Although resident baselines in other studies were obtained post-relocation, several residents were in the assisted living facility over a week before being interviewed, allowing some adjustment or intervention to take place prior to entry into the study. Thus, differences in the adjustment variables between time 1 and time 2 may have been reduced. Finally, residents may have experienced cognitive dissonance, wanting to present in a positive light to reduce distress over the move. They may also have been hesitant to report negative symptoms due to the decline in their abilities potentially leading to relocation, or the desire to be seen positively. Residents may have presented themselves positively at first, but felt more comfortable in the facility and with the study by time 3, resulting in more accurate self-reporting. Therefore, response bias may have lessened the short-term differences, and a change in response bias, not actual decline, may have resulted in declines by time 3 . As predicted, community residents demonstrated no significant differences on the adjustment variables as a result of time.

\section{Group Differences on Adjustment Variables}

Assisted living residents were significantly less satisfied with their life at time 3 than community residents. This result expands upon those reported by Gonzalez-Salvador (2000) showing assisted living residents to have greater life satisfaction than nursing home residents. This further promotes the idea that assisted living is a middle ground between community 
Adjustment to Assisted Living 46 dwelling and residing in a nursing home. However, it also highlights the lowered life satisfaction among residents of assisted living in comparison to community dwelling older adults.

Although no significant differences on the other adjustment variables were found between groups at any time, assisted living residents showed greater levels of anxiety, negative affect, IADL impairment, and depression than community residents at all three assessments. The findings support research by Grayson et al. (1995) regarding depression in assisted living residents, but given the non-significance of the differences, these findings suggest the potential of a factor other than relocation influencing previous findings on adjustment to relocation, possibly social support or health as suggested by Borup (1983). Social support is related to psychological well being and coavarying it in the current study may have reduced the differences found in previous research. Health has been related to depression and life satisfaction (Mitchell \& Kemp, 2000), so it is possible that health status influenced the non-significance of results in the current study. The recruitment of an appropriate control group with health similar to assisted living residents likely resulted in smaller differences between groups in the current study than would be seen in comparison to a randomly selected group of older community residents.

Both the community dwelling older adults and residents of assisted living were clinically distressed. On the instruments used in the current study that provide suggested clinical cutoff points for clinical significance, both group means exceeded those cutoff points. For example, both group means exceeded the suggested cutoff point for depression on the GDS15 (Almeida \& Almeida, 1999), with 11 assisted living and 9 community residents meeting the cutoff score, suggesting that both groups contained individuals experiencing at least mild levels of depression. In addition, both groups yielded mean BAI scores indicative of mild to moderate anxiety (Beck \& Steer, 1990). One assisted living and 2 community residents were classified as exhibiting 
severe anxiety, 6 assisted living and 2 community residents were classified as exhibiting moderate to severe anxiety, 4 assisted living and 4 community residents were classified as exhibiting mild to moderate anxiety, and 7 assisted living and 11 community residents were classified as exhibiting normal levels of anxiety. Moreover, mean health ratings for both groups reflected only "fair" health. Finally, IADL scores in both groups indicated some impairment in roughly two to four instrumental activities of daily living. Thus, despite residential status, older adults with functional impairment appear to have a high degree of psychological and physical morbidity.

\section{$\underline{\text { Desired Versus Actual Control }}$}

Assisted living residents demonstrated greater mismatches between desired and actual control than community residents, reaching significance at time 3 . Both assisted living residents and community dwelling older adults had less control than they desired at all three time periods, however, at time 3 the magnitude of the discrepancy was significantly greater among assisted living residents. The significant difference at time 3 reflects greater lack of control than desired among assisted living residents than among community dwelling older adults. Residing in assisted living appears to result in a greater difference between desired and actual control than remaining in the community. This may be due to the increased supervision or greater structure provided in assisted living facilities. It may also reflect greater experience with assisted living and limitations on control within a facility. Often in institutional settings, residents' dependent behavior is rewarded with supportive reactions by staff while independent behavior is largely ignored. Baltes and Wahl (1992) describe this pattern as the dependency-support script. This pattern is seen in all types of caregiving situations, both within nursing homes and community settings, and may lead to declines in actual functional abilities among older adults in institutional 
settings. Moreover, interventions aimed at reducing this interaction pattern lead to improved self-care among older adults in residential settings (Baltes, Neumann, \& Zank, 1994). Thus declines in the experience of control among assisted living residents in the current study may be related to the behavioral response patterns of the staff of assisted living to independent self-care behaviors. However, differences in actual and desired control between assisted living and community residents may also reflect the greater ability of community residents to change aspects of their environment related to control (e.g., ignore the advice of a doctor, limit the amount of contact they have with others). Either way, it suggests that assisted living does limit, whether explicitly or in the nature of the housing, the amount of control older adult's experience. $\underline{\text { Physical and Psychological Health Changes Over Time }}$

Although differences did not reach significance, assisted living residents experienced greater amounts of change than community residents on all variables at all times. The failure of differences to reach significance is puzzling, although sample size may have been an issue. As proposed earlier, relocation to an assisted living facility may provide a stabilizing environment for older adults with declining health and functional problems. Residing in a controlled environment may also decrease stress among residents due to decreased responsibility or negative experiences (e.g., fear of falling and not being found). Residents remaining in the community do not benefit from this and may continue to experience psychological distress. However, given the relation between control and adjustment and the previously discussed results, this interpretation of the data is given with caution.

\section{Control and Adjustment}

Perceived decisional control was moderately related to depression at entry into an assisted living facility, but was not related to any other adjustment variable at any other time. 
Adjustment to Assisted Living 49

The findings on control and depression support previous research by Kasl and Rosenfield (1980) that found control over relocation to be related to depression. However, research by Thomasma et al. (1990) and Pino, Rosica, and Carter (1978) showed decisional control to be related to anxiety and life-satisfaction in nursing home residents, in contrast to the low, non-significant relations between decisional control and both anxiety and life satisfaction in the current study. Given the earlier finding regarding willingness to relocate, perhaps the current group of assisted living residents was more willing to move than in the previous studies and experienced less psychological distress as a result. Additionally, assisted living residences may present a less severe change and therefore be less distressful. Moreover, actual control was highly related to depression, life satisfaction, and affect at time 3, with higher control related to lower depression and anxiety levels, and higher reported life satisfaction. Changes in actual control may have a greater impact on adjustment than changes in perceptions of control and the desire for control. Finally, all relations increased in strength over time suggesting that a lack of control may have cumulative effects on psychological adjustment. Therefore, early intervention may be important in this population.

\section{$\underline{\text { Control and Health }}$}

Health was significantly related to decisional control. This reinforces Rodin's (1986a) and Smits, Deeg, and Bosscher's (1995) findings on control and health in nursing home residents and community dwelling older adults. People with better health are more physically capable of influencing decisions and exert greater levels of control than individuals with poor health, who need more assistance and exert less control. Functional and physical health were also moderately related to actual control, but not desired control in the present study. Desired control may not be related to physical health or ability due to the nature of desired control. Desired control requires 
Adjustment to Assisted Living 50

no relation to physical ability, simply perceptions on control. An individual can have a high

desire for ability but no actual physical ability to exert control. However, actual control is directly related to physical ability and health. People with better health and less functional impairment are more likely to be able to exert and experience control than those who are more impaired. Thus, as health declines, so does one's ability to have control. These moderate relations support the hypothesis that health plays a factor in the adjustment variables previously discussed.

\section{Limitations}

Several limitations must be addressed regarding interpretation of the results of this study. The small sample size in the current study limited the likelihood of finding statistically significant differences between the groups. Although many differences were found between the groups, few reached significance. Although these findings may reflect a true lack of differences between the two populations, particularly given the relatively equal health levels, the low level of power produced by the small sample may have resulted in a high rate of Type II errors. Thus, it cannot be concluded that true differences do not exist. However, significant differences found in the small sample, such as differences in social support and life satisfaction, likely reflect true differences given the effect size required to produce such differences. All findings should be reviewed with the small sample size in mind.

It should also be noted that the results obtained with the assisted living sample cannot be generalized to all assisted living residents. Only 32 percent of potential participants qualified and completed the study. While it is likely that results can be generalized to relatively cognitively intact individuals relocating permanently to assisted living, results may not apply to the entire population of assisted living residents, including older adults residing in assisted living for shorter periods of time or cognitively impaired residents. 
Adjustment to Assisted Living 51

The collection of data post-relocation also is potentially problematic. Although

significant findings have been demonstrated in relocation research when baseline is obtained post-relocation (e.g., Davidson \& O'Conner, 1990), the use of a post-relocation baseline may have diminished differences between time 1 and time 2 because both assessments captured adjustment within the first month following relocation.

Finally, some concerns with the measures should be addressed. Assisted living residents had a difficult time completing several instruments, resulting in the measures being administered orally. Having to respond verbally may have encouraged residents to present their psychological status in a positive light. In addition, the oral presentation may not have eliminated all problems with interpreting some of the questions. The DSC-SF and LSI-Z both contain items with negatives in them that residents frequently asked to be repeated. Answers may not have captured resident's true responses due to the amount of interpretation required to answer them.

\section{Future Directions}

As with the completion of most research, additional questions were raised with the conclusions of this research. The roles of health, social support, and control are intermingled and appear to play a role in the adjustment to relocation. In addition, they each play a role in the psychological well-being of older adults regardless of relocation status. The role of health is of particular interest due to many varied facets of health. Future research needs to address the measurement of health and the particular aspects within any definition of health that influence psychological health. The development of a comprehensive measure of health would benefit research with older adults and other populations.

Replication of this study with a larger sample could clarify some of the questions raised by this study. Assisted living residents did not show the typical adjustment pattern seen in 
Adjustment to Assisted Living 52

nursing home residents following relocation. If this is a true finding, and can be replicated with a pre-relocation assessment and a larger sample, discovering the reasons assisted living facilities reduce the negative impact of relocation could assist in making relocation into other settings less traumatic or detrimental to residents.

The levels of depression, anxiety, and poor life satisfaction found in both groups of residents indicate a great deal of distress among older adults with functional impairment. Future research on interventions aimed at reducing this distress or diminishing the impact of functional impairment on psychological well-being is needed to ensure greater quality of life among functionally impaired older adults.

Further research on the relation between actual control and adjustment could lead to interventions aimed at reducing poor adjustment by increasing actual control within an assisted living residence. Simple strategies such as control over meal times or destinations of outings may increase resident satisfaction with life and residence.

An unintended finding in this research involves community residents' perceptions of assisted living. Many community residents might benefit from increased assistance but eliminate the possibility of relocation into assisted living. Research on the actual perceptions of older adults in regard to residential setting is needed to understand the reasons behind these perceptions. This could lead to information that can be used to develop programs to increase individual's use of formal caregiving services, not just in assisted living, but in home health and respite care as well.

Finally, more research on control over relocation is needed, particularly in regard to the differences between actual control and willingness to relocate. Decisional control was not related to adjustment to assisted living in this study. However, actual environmental control was highly 
Adjustment to Assisted Living 53

related to depression, life satisfaction, and affect. Clarifying the relations between these variables and health could guide the development of intervention programs aimed at increasing opportunities for control in older adults and mitigating the effects of a lack of control. Further research in this area will help improve the quality of life for residents of assisted living and atrisk older adults residing in the community. 


\section{References}

Adjustment to Assisted Living 54

Aldrich, C. K., \& Mendkoff, E. (1963). Relocation of the aged and disabled: A mortality study. Journal of the American Geriatrics Society, 11, 185-194.

Almeida, O. P., \& Almeida, S. A. (1999). Short versions of the Geriatric Depression Scale: A study of their validity for the diagnosis of a major depressive episode according to ICD10 and DSM-IV. International Journal of Geriatric Psychiatry, 14, 858-865.

Antonucci, T. C. (1990). Social supports and social relationships. In R. H. Binstock \& L. K. George (Eds.), Handbook of aging and the social sciences (3rd ed., pp. 205-227). San Diego: Academic Press.

Arling, G., Harkins, E. B., \& Capitman, J. A. (1986). Institutionalization and personal control: A panel study of impaired older people. Research on Aging, 8(1), 38-56.

Armer, J. M. (1993). Elderly relocation to a congregate setting: Factors influencing adjustment. Issues in Mental Health Nursing, 14, 157-172.

Armer, J. M. (1996). An exploration of factors influencing adjustment among relocating rural elders. IMAGE: Journal of Nursing Scholarship, 28, 35-39.

Ayalon, L., \& Huyck, M. H. (2001). Latino caregivers of relatives with Alzheimer's disease. Clinical Gerontologist, 24(3-4), 93-106.

Baglioni, A. J. (1989). Residential relocation and health of the elderly. In K. S. Markides \& C. L. Cooper (Eds.), Aging, stress, and health (pp. 120-137). New York: John Wiley \& Sons. Baltes, M. M., Neumann, E., \& Zank, S. (1994). Maintenance and rehabilitation of independence in old age: An intervention program for staff. Psychology and Aging,9, 179-188.

Baltes, M. M. \& Wahl, H. (1992). The dependency-support script in institutions: Generalization to community settings. Psychology and Aging, 7, 409-418. 
Beaver, M. L. (1979). The decision-making process and its relationship to relocation adjustment in old people. The Gerontologist, 19, 567-574.

Beck, A. T., Epstein, N., Brown, G., \& Steer, R. A. (1988). An inventory for measuring clinical anxiety: Psychometric properties. Journal of Consulting and Clinical Psychology, 56, 893-897.

Beck, A. T., \& Steer, R. A. (1990). Beck Anxiety Inventory Manual. San Antonio: The Psychological Corporation.

Birren, J. E. (1965). Reactions to loss and the process of aging: Interrelations of environmental changes, psychological capacities, and physiological status. In M. A. Berezin \& S. H. Cath (Eds.), Geriatric psychiatry: Grief, loss, and emotional disorders in the aging process. New York: International Universities Press.

Blenkner, M. (1967). Environmental change and the aging individual. The Gerontologist, 7, 101-105.

Borup, J. (1982). The effects of varying degrees of interinstitutional environmental change on long-term care patients. The Gerontologist, 22, 409-417.

Borup, J. (1983). Relocation mortality research: Assessment, reply, and the need to refocus on the issues. The Gerontologist, 23, 235-242.

Bourestom, N. (1984). Psychological and physiological manifestations of relocation. Psychiatric Medicine, 2, 57-90.

Bourestom, N., \& Pastalan, L. (1981). The effects of relocation on the elderly: A reply to a response from Borup and Gallego. The Gerontologist, 21, 4-16.

Bourestom, N., \& Tars, S. (1974). Alterations in life patterns following nursing home relocation. The Gerontologist, 14, 506-510. 
Adjustment to Assisted Living 56

Bowsher, J. E., \& Gerlach, M. J. (1990). Personal control and other determinants of psychological well-being in nursing home elders. Scholarly Inquiry for Nursing Practice: An International Journal, 4, 91-102.

Bradley, R. H., \& Webb, R. (1976). Age-related differences in locus of control orientation in three behavior domains. Human Development, 19, 49-55.

Brammer, L. M. (1992). Coping with life transitions. International Journal for the Advancement of Counselling, 15, 239-253.

Brand, F. N., \& Smith, R. T. (1974). Life adjustment and relocation of the elderly. Journal of Gerontology, 29, 336-340.

Burman, B., \& Margolin, G. (1992). Analysis of the association between marital relationships and health problems: An interactional perspective. Psychological Bulletin, 112, 3963.

Carmago, O., \& Preston, G. H. (1945). What happens to patients who are hospitalized for the first time when over sixty-five years of age? American Journal of Psychiatry, 102, 168-173.

Clark, P. G. (1988). Autonomy, personal empowerment, and quality of life in long-term care. The Journal of Applied Gerontology, 7, 279-297.

Cohen, J. \& Cohen, P. (1983). Applied multiple regression/correlational analysis for the behavioral sciences - second edition. Hillsdale, NJ: Lawrence Erlbaum Associates.

Coleman, P. (1990). Adjustment in later life. In J. Bond \& P. Coleman (Eds.), Aging in society: An introduction to social gerontology (pp. 89-128). London: SAGE Publications.

Corah, N. L., \& Boffa, J. (1970). Perceived control, self-observation, and response to aversive stimulation. Journal of Personality and Social Psychology, 16, 1-4. 
Coulton, C. J., Dunkle, R. E., Chow, J. C., Haug, M., \& Vielhaber, D. P. (1988).

Dimensions of post-hospital care decision-making: A factor analytic study. The Gerontologist, $\underline{28}, 218-223$.

Coulton, C. J., Dunkle, R. E., Goode, R. A., \& MacKintosh, J. (1982). Discharge planning and decision making. Health and Social Work, 7, 253-261.

Curran, S. L., Andrykowski, M. A., \& Studts, J. L. (1995). Short Form of the Profile of Mood States (POMS-SF): Psychometric information. Psychological Assessment, 7(1), 80-83.

Danermark, B., \& Ekström, M. (1990). Relocation and health effects on the elderly: A commented research review. Journal of Sociology and Social Welfare, 17(1), 25-49.

Davidson, H. A., \& O’Connor, B. P. (1990). Perceived control and acceptance of the decision to enter a nursing home as predictors of adjustment. International Journal of Aging and Human Development, 31, 307-318.

Drozdick, L. W. (Unpublished). Decisional control and adjustment to relocation to a nursing home. Doctoral Qualification Examination: West Virginia University.

Edelstein, B. A., Kalish, K. D., Drozdick, L. W., \& McKee, D. R. (1999). Assessment of depression and bereavement in older adults. In P. A. Lichtenberg (Ed.), Handbook of assessment in clinical gerontology (pp 11-58). New York: John Wiley \& Sons, Inc.

Fisher, J. E., \& Noll, J. P. (1996). Anxiety disorders. In L. L. Carstensen, B. A. Edelstein, \& L. Dornbrand (Eds.), The practical handbook of clinical gerontology (pp. 304-323). Thousand Oaks, California: SAGE Publications.

Folstein, M., Folstein, S., \& McHugh, P. (1975). "Mini-Mental State": A practical method for grading the cognitive state of patients for the clinician. Journal of Psychiatric Research, 12, 189-198. 
Adjustment to Assisted Living 58

Frytak, J. R., Kane, R. A., Finch, M. D., Kane, R. L., \& Maude-Griffin, R. (2001).

Outcome trajectories for assisted living and nursing facility residents in Oregon. Health Services

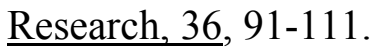

Gabrel, C., \& Jones, A. (2000). The national nursing home survey: 1995 summary. (National Center for Health Statistics Publication No. 13-146). Washington, DC; Government Printing Office.

George, L. K. (2001). The social psychology of health. In R. H. Binstock \& L. K. George (Eds.), Handbook of aging and the social sciences (Fifth Edition, pp. 217-237). San Diego: Academic Press.

Gilderbloom, J. I., \& Mullins, R. L. (1995). Elderly housing needs: An examination of the American housing survey. International Journal of Aging and Human Development, 40, 57 72.

Gonzalez-Salvador, T., Lyketsos, C. G., Baker, A., Hovanec, L., Roques, C., Brandt, J., \& Steele, C. (2000). Quality of life in dementia patients in long-term care. International Journal of Geriatric Psychiatry, 15, 181-189.

Grant, P. R., Skinkle, R. R., \& Lipps, G. (1992). The impact of an interinstitutional relocation on nursing home residents requiring a high level of care. The Gerontologist, 32, 834842.

Grayson, P., Lubin, B., \& VanWhitlock, R. (1995). Comparison of depression in the community-dwelling and assisted-living elderly. Journal of Clinical Psychology, 51, 18-21.

Harel, Z., \& Noelker, L. (1982). Social integration, health, and choice: Their impact on the well-being of institutionalized aged. Research on Aging, 4, 97-111. 
Hawes, C., Phillips, C. D., \& Rose, M. (2000). High service or high privacy assisted living facilities, their residents and staff: Results from a national survey. Washington, DC: United States Department of Health and Human Services.

Hawes, C., Rose, M., \& Phillips, C. D. (1999). A national study of assisted living for the frail elderly: Results of a national survey of facilities. Washington, DC: United States Department of Health and Human Services.

Idler, E. L., \& Kasl, S. (1991). Health perceptions and survival: Do global evaluations of health status really predict mortality? Journal of Gerontology, 46, S55-S65.

Kabacoff, R. I., Segal, D. L., Hersen, M., \& Van Hasselt, V. B. (1997). Psychometric properties and diagnostic utility of the Beck Anxiety Inventory and the State-Trait Anxiety Inventory with older adult psychiatric outpatients. Journal of Anxiety Disorders, 11, 33-47.

Kane, R. A., Illston, L. H., Kane, R. L., \& Nyman, J. A. (1990). Meshing services with housing: Lessons from adult foster care and assisted living in Oregon. Minneapolis, MN: University of Minnesota School of Public Health.

Kane, R. A., \& Wilson, K. B. (1993). Assisted living in the United States: A new paradigm for residential care for frail older persons? Washington, DC: AARP Public Policy Institute.

Kasl, S. V. (1972). Physical and mental health effects of involuntary relocation and institutionalization on the elderly: A review. American Journal of Public Health, 62, 377-384.

Kasl, S. V., \& Rosenfield, S. (1980). The residential environment and its impact on the mental health of the aged. In J. Birren \& R. Sloane (Eds.), Handbook of mental health and aging (pp. 468-498). Englewood Cliffs, New Jersey: Prentice-Hall. 
Keslosky, M. A., \& Stevens, G. L. (1999). The assisted living industry: An industry overview and performance analysis of public firms. Lancaster, PA: Franklin and Marshall College.

Konnert, C., \& Crowhurst, B. (1996, November). A longitudinal study of perceived control, social support, and depression in relocating elderly. Paper presented at the annual meeting of the Gerontological Society of America, Washington, DC

Kraus, N., \& Altman, B. (1998). Characteristics of nursing home residents - 1996. (AHCPR Publication Number 99-0006). Rockville, MD: Agency for Health Care Policy and Research.

Kraus, N., Machlin, S., \& Kass, B. (1999). Use of health care services, 1996. (AHCPR Publication Number 99-0018). Rockville, MD: Agency for Health Care Policy and Research. Lachman, M. E. (1986). Personal control in later life: Stability, change, and cognitive correlates. In M. M. Baltes \& P. B. Baltes (Eds.), The psychology of control and aging (pp 207236). Hillsdale, NJ: Lawrence Erlbaum Associates.

Langer, E. J., \& Rodin, J. (1976). The effects of choice and enhanced personal responsibility for the aged: A field experiment in an institutional setting. Journal of Personality and Social Psychology, 34, 191-198.

Lawton, M. P., \& Brody, E. M. (1969). Assessment of older people: Self-maintaining and instrumental activities of daily living. The Gerontologist, 9, 179-186.

Lawton, M. P., \& Lawrence, R. H. (1994). Assessing health. In M. P. Lawton \& J. A. Teresi (Eds.), Annual review of gerontology and geriatrics: Focus on assessment techniques (Vol. 14, pp. 23-56). New York: Springer Publishing Company. 
Adjustment to Assisted Living 61

Lawton, M. P., \& Yaffe, S. (1970). Mortality, morbidity, and voluntary change of residence by older people. Journal of the American Geriatrics Society, 18, 823-831.

Lefcourt, H. M. (1991). Locus of control. In J. P. Robinson, P. R. Shaver, \& L. S. Wrightsman (Eds.), Measures of personality and social psychological attitudes. (pp. 413-499). San Diego: Academic Press.

Levkoff, S., Levy, B., \& Weitzman, P. F. (1999). The role of religion and ethnicity in the help seeking of family caregivers of elders with Alzheimer's disease and related disorders. Journal of Cross-Cultural Gerontology, 14, 335-356.

Maddox, G. L. (2001). Housing and living arrangements: A transactional perspective. In R. H. Binstock \& L. K. George (Eds.), Handbook of aging and the social sciences (Fifth Edition, pp. 426-443). San Diego: Academic Press.

Maddox, G. L., Atchley, R. C., Poon, L. W., Roth, G. S., Siegler, I. C., \& Steinberg, R. M. (1987). The encyclopedia of aging. New York: Springer Publishing Co.

Maddox, G. L., \& Douglass, E. B. (1973). Self-assessment of health: A longitudinal study of elderly subjects. Journal of Health and Social Behavior, 14, 87-93.

Manard, B. B., \& Cameron, R. (1997). National study of assisted living for the frail elderly. Washington, D.C.: Lewin-VHI, Inc.

Markson, E. W., \& Cumming, J. H. (1974). A strategy of necessary mass transfer and its impact on patient mortality. Journal of Gerontology, 29, 315-321.

Mikhail, M. L. (1992). Psychological responses to relocation to a nursing home. Journal of Gerontological Nursing, March, 35-39.

Minichiello, V. (1986). Social process in entering nursing homes. In H. Kendig (Ed.). Aging and families: A support networks perspective (pp. 149-168). Sydney: Allen \& Unwin. 
Adjustment to Assisted Living 62

Mirowsky, J. (1995). Age and the sense of control. Social Psychology Quarterly, 58, 31-

43.

Mitchell, J. M., \& Kemp, B. J. (2000). Quality of life in assisted living homes: A multidimensional analysis. Journal of Gerontology: Psychological Sciences, 55B, P117-P127.

Moos, R. \& Lemke, S. (1992). Resident and staff information form manual. Palo Alto, CA.: Department of Veterans Affairs and Stanford University Medical Centers.

Mossey, J. M., \& Shapiro, E. (1982). Self-rated health: A predictor of mortality among the elderly. American Journal of Public Health, 72, 800-808.

Navaie-Waliser, M., Feldman, P. H., Gould, D. A., Levine, C., Kuerbis, A. N., \& Donelan, K. (2001). The experiences and challenges of informal caregivers: Common themes and differences among Whites, Blacks, and Hispanics. The Gerontologist, 41, 733-741.

National Center for Assisted Living (1998). Facts and trends: The assisted living sourcebook. National Center for Assisted Living.

National Center for Cost Containment. (1996). Geropsychology assessment resource guide: 1996 revision. Milwaukee, WI: NCCC, Department of Veterans Affairs.

Nay, R. (1995). Nursing home residents' perceptions of relocation. Journal of Clinical Nursing, 4, 319-325.

Neugarten, B. L., Havighurst, R. J., \& Tobin, S. S. (1961). The measurement of life satisfaction. Journal of Gerontology, 16, 134-143.

Newsom, J. T., Bookwala, J., \& Schulz, R. (1997). Social support measurement in group residences for older adults. In J. A. Teresi, M. P. Lawton, D. Holmes, \& M. Ory (Eds.), Measurement in elderly chronic care populations (pp. 157-177). New York: Springer Publishing Company. 
Noelker, L., \& Harel, Z. (1978). Predictors of well-being and survival among institutionalized aged. The Gerontologist, 18, 562-567.

Norbeck, J. S., Lindsey, A., \& Carrieri, V. L. (1981). The development of an instrument to measure social support. Nursing Research, 30, 264-269.

Olin, J. T., Schneider, L. S., Eaton, E. M., Zemansky, M. F., \& Pollock, V. E. (1992). The Geriatric Depression Scale and the Beck Depression Inventory as screening instruments in an older adult outpatient population. Psychological Assessment, 4(2), 190-192.

Pablo, R. Y. (1977). Intra-institutional relocation: Its impact on long-term care patients. The Gerontologist, 17, 426-435.

Parmelee, P. A., Katz, I. R., \& Lawton, M. P. (1989). Depression among institutionalized aged: Assessment and prevalence estimation. Journals of Gerontology, 44, M22-M29.

Perlmuter, L. C., Monty, R. A., \& Chan, F. (1986). Choice, control, and cognitive functioning. In M. M. Baltes \& P. B. Baltes (Eds.), The psychology of control and aging (pp. 91118). Hillsdale, NJ: Lawrence Erlbaum Associates.

Phillips, C., Hawes, C., Green, R., \& Norton, E. (1998). Medicare utilization among board and care residents. Beachwood, OH: Myers Research Institute, Menorah Park Center for Senior Living.

Pino, C. J., Rosica, L. M., \& Carter, T. J. (1978). The differential effects of relocation on nursing home patients. The Gerontologist, 18, 167-172.

Pohl, J. M., \& Fuller, S. S. (1980). Perceived choice, social interaction, and dimensions of morale of residents in a home for the aged. Research in Nursing and Health, 3, 147-157.

Pruchno, R. A., \& Rose, M. S. (2000). The effect of long-term care environments on health outcomes. The Gerontologist, 40, 422-428. 
Adjustment to Assisted Living 64

Reid, D. W., \& Zeigler, M. (1981). The desired control measure and adjustment among

the elderly. In H. M. Lefcourt (Ed.), Research with the locus of control construct (volume 1): Assessment methods (pp. 127-158). New York: Academic Press.

Reinardy, J. R. (1992). Decisional control in moving to a nursing home: Postadmission adjustment and well-being. The Gerontologist, 32, 96-103.

Reinardy, J. R. (1995). Relocation to a new environment: Decisional control and a move to a nursing home. Health and Social Work, 20, 31-38.

Rodin, J. (1986a). Aging and health: Effects of the sense of control. Science, 233, 12711276.

Rodin, J. (1986b). Health, control, and aging. In M. M. Baltes \& P. B. Baltes (Eds.), The psychology of control and aging (pp. 139-166). Hillsdale, NJ: Lawrence Erlbaum Associates.

Rook, K. S. (1994). Assessing the health-related dimensions of older adults' social relationships. In M. P. Lawton \& J. A. Teresi (Eds.), Annual review of gerontology and geriatrics: Focus on assessment techniques (Vol. 14, pp. 142-181). New York: Springer Publishing Company.

Rose, J. W. (2002). Validity and reliability of the Geriatric Depression Scale with the elderly residing in assisted living facilities. Dissertation Abstracts International, 62(9A), 2981.

Rowland, K. F. (1977). Environmental events predicting death for the elderly. Psychological Bulletin, 84, 349-372.

Sahyoun, N. R., Pratt, L. A., Lentzner, H., Dey, A., \& Robinson, K. N. (2001). The changing profile of nursing home residents: 1985-1997. Aging Trends (4), 1-8. 
Adjustment to Assisted Living 65

Schulz, R. (1976). Effects of control and predictability on the physical and psychological well-being of the institutionalized aged. Journal of Personality and Social Psychology, 33, 563573.

Schulz, R., \& Brenner, G. (1977). Relocation of the aged: A review and theoretical analysis. Journal of Gerontology, 32, 323-333.

Schulz, R., \& Hanusa, B. H. (1978). Long-term effects of control and predictabilityenhancing interventions: Findings and ethical issues. Journal of Personality and Social Psychology, 36, 1194-1201.

Schulz, R., O'Brien, A. T., \& Tompkins, C. A. (1994). The measurement of affect in the elderly. In M. P. Lawton \& J. A. Teresi (Eds.), Annual review of gerontology and geriatrics: Focus on assessment techniques (Vol. 14, pp. 210-233). New York: Springer Publishing Company.

Seligman, M. E. P. (1975). Helplessness: On depression, development, and death. San Francisco: W. H. Freeman.

Shacham, S. (1983). A shortened version of the Profile of Mood States. Journal of Personality Assessment, 47, 305-306.

Shapiro, D. H., Schwartz, C. E., \& Astin, J. A. (1996). Controlling ourselves, controlling our world: Psychology's role in understanding positive and negative consequences of seeking and gaining control. American Psychologist, 51, 1213-1230.

Sheikh, J. I., \& Yesavage, J. A. (1986). Geriatric Depression Scale (GDS): Recent evidence and development of a shorter version. In T. L. Brink (Ed.), Clinical gerontology: A guide to assessment and intervention (pp. 165-173). New York: Haworth Press. 
Adjustment to Assisted Living 66

Sherwood, S., Glassman, J., Sherwood, C., \& Morris, J. N. (1974). Pre-

institutionalization factors as predictors of adjustment to a long-term care facility. International Journal of Aging and Human Development, 5, 95-105.

Sikorska, E. (1999). Organizational determinants of resident satisfaction with assisted living. The Gerontologist, 39, 450-456.

Smits, C. H. M., Deeg, D. J. H., \& Bosscher. R. J. (1995). Well-being and control in older persons: The prediction of well-being from control measures. International Journal of Aging and Human Development, 40, 237-251.

Thomasma, M., Yeaworth, R., \& McCabe, B. (1990). Moving day: Relocation and anxiety in institutionalized elderly. Journal of Gerontological Nursing, 16(7), 18-25.

Timko, C., \& Moos, R. H. (1989). Choice, control, and adaptation among elderly residents of sheltered care settings. Journal of Applied Social Psychology, 19, 636-655.

Tobin, S. S. (1989). The effects of institutionalization. In K. S. Markides \& C. L. Cooper (Eds.), Aging, stress, and health (pp. 139-163). New York: John Wiley \& Sons, Ltd.

Tobin, S. S., \& Lieberman, M. A. (1976). Last home for the aged: Critical implications of institutionalization. San Francisco: Jossey-Bass.

Watson, C. G., \& Buerckle, H. R. (1976). Involuntary transfer as a cause of death and of medical hospitalization in geriatric neuropsychiatric patients. Journal of the American Geriatrics Society, 24, 278-282.

Wetherell, J. L., \& Arean, P. A. (1997). Psychometric evaluation of the Beck Anxiety Inventory with older medical patients. Psychological Assessment, 9, 136-144. 
Adjustment to Assisted Living 67

White, C. B., \& Janson, P. (1986). Helplessness in institutional settings: Adaptation or iatrogenic disease? In M. M. Baltes \& P. B. Baltes (Eds.), The psychology of control and aging (pp. 297-314). Hillsdale, NJ: Lawrence Erlbaum Associates.

Wilmoth, J. M. (1998). Living arrangement transitions among America’s older adults. The Gerontologist, 38, 434-444.

Wolinsky, F. D., Callahan, C. M., Fitzgerald, J. F., \& Johnson, R. J. (1992). The risk of nursing home placement and subsequent death among older adults. Journal of Gerontology: Social Sciences, 47, S173-S182.

Wolinsky, F. D., \& Stump, T. E. (1996). Age and the sense of control among older adults. Journal of Gerontology: Social Sciences, 51B, S217-S220.

Wolk, S., \& Telleen, S. (1976). Psychological and social correlates of life satisfaction as a function of residential constraint. Journal of Gerontology, 31, 89-98.

Wood, V., Wylie, M. L., \& Sheafor, B. (1969). An analysis of a short, self-report measure of life satisfaction: Correlation with rater judgments. Journal of Gerontology, 24, 465469. 
Table 1

Adjustment to Assisted Living 68

Characteristics of Assisted Living and Nursing Homes Residents

\begin{tabular}{lll}
\hline Characteristic & Assisted Living Residents & Nursing Home Residents \\
\hline Predominant ethnicity & $99 \%$ white & $88 \%$ white \\
\hline Gender & $79 \%$ female & $73 \%$ female \\
\hline Mean age & 84.5 & 83 \\
\hline Marital Status & $71 \%$ widowed & $60 \%$ widowed \\
\hline $\begin{array}{l}\text { Percent with Cognitive } \\
\text { Impairment }\end{array}$ & $\begin{array}{l}27 \% \text { moderately - severely } \\
\text { impaired }\end{array}$ & $60-70 \%$ severely impaired \\
\hline $\begin{array}{l}\text { Percent requiring assistance } \\
\text { with IADL }\end{array}$ & 77 & 77 \\
\hline $\begin{array}{l}\text { Percent requiring assistance } \\
\text { with ADL }\end{array}$ & 21 & 96 \\
\hline $\begin{array}{l}\text { Hospital Usage } \\
\text { Length of Residence }\end{array}$ & $\begin{array}{l}24 \% \text { used ER in past } 12 \\
\text { months; 32\% had an overnight } \\
\text { stay stay }\end{array}$ & $26 \%$ had an overnight hospital \\
\hline 20 months & 29 months \\
\hline
\end{tabular}

Data obtained from (Gabrel \& Jones (2000); Hawes, Phillips, \& Rose (2000); Kraus \& Altman (1998); Krauss, Machlin, \& Kass (1999); Phillips, Hawes, Green, \& Norton (1998); Sahyoun, Pratt, Lentzner, Dey, \& Robinson (2001)) 
Table 2

Reasons for Assisted Living Residents Nonparticipation

\begin{tabular}{lc}
\hline Reason & Number of Residents \\
\hline Included in study & 18 \\
$\begin{array}{l}\text { Planned a stay of less than 3 months, typically } \\
\text { for recovery from a prolonged hospital stay }\end{array}$ & 19 \\
$\begin{array}{l}\text { Failed cognitive screening and thus too } \\
\text { impaired to participate }\end{array}$ & 10 \\
$\begin{array}{l}\text { Refused, declined to participate in first two } \\
\text { weeks, lacked ability to consent, or family } \\
\text { refused to provide consent }\end{array}$ & 8 \\
Utilized Spanish as a primary language & 2 \\
\hline
\end{tabular}


Table 3

Adjustment to Assisted Living 70

Number of Participants Completing Evaluations at Each Time Period, by Group

\begin{tabular}{lccc}
\hline Group & Number at Time 1 & Number at Time 2 & Number at Time 3 \\
\hline Assisted Living & 18 & 18 & 16 \\
Community & 19 & 19 & 19 \\
\hline
\end{tabular}


Table 4

Adjustment to Assisted Living 71

Demographic Characteristics of the Assisted Living and Community Dwelling Groups

\begin{tabular}{|c|c|c|}
\hline Variable & Assisted Living & Community Dwelling \\
\hline Age * & $X=79.61 ; S D=7.19 ;$ Range $63-93$ & $X=73.26 ; S D=10.36 ;$ Range $60-89$ \\
\hline Gender & 13 female, 5 male & 11 female, 8 male \\
\hline Ethnicity * & 17 Caucasian, 1 Hispanic & 13 Caucasian, 6 Hispanic \\
\hline Marital Status * & $\begin{array}{c}10 \text { widowed, } 3 \text { married, } 4 \text { divorced, } 1 \\
\text { single }\end{array}$ & $\begin{array}{l}5 \text { widowed, } 9 \text { married, } 4 \text { single, } 1 \\
\text { divorced }\end{array}$ \\
\hline Living Status * & 14 alone, 2 spouse, 2 roommate & $\begin{array}{c}8 \text { alone, } 9 \text { spouse, } 1 \text { children, } 1 \\
\text { renter }\end{array}$ \\
\hline $\begin{array}{l}\text { Number reporting } \\
\text { Medical Conditions }\end{array}$ & 18 & 17 \\
\hline $\begin{array}{l}\text { Number taking } \\
\text { Prescriptions }\end{array}$ & 18 & 17 \\
\hline $\begin{array}{l}\text { Functional Social } \\
\text { Support at Time } 1 *\end{array}$ & $\begin{aligned} X= & 98.50 ; \mathrm{SD}=61.95 \\
& \text { Range } 28-285\end{aligned}$ & $\begin{array}{c}X=165.11 ; \mathrm{SD}=89.91 \\
\text { Range } 18-335\end{array}$ \\
\hline $\begin{array}{l}\text { Network Strength } \\
\text { at Time } 1^{*}\end{array}$ & $\begin{array}{c}\mathrm{X}=51.28 ; \mathrm{SD}=28.38 \\
\quad \text { Range } 17133\end{array}$ & $\begin{aligned} X= & 94.74 ; S D=52.92 ; \\
& \text { Range } 11-210\end{aligned}$ \\
\hline Loss at Time 1 & $\mathrm{X}=2.67 ; \mathrm{SD}=2.89 ;$ Range $0-7$ & $X=1.26 ; S D=2.64 ;$ Range $0-7$ \\
\hline
\end{tabular}

*Significant at the .05 level. 
Table 5

Adjustment to Assisted Living

Percent of Assisted Living Residents Reporting Various Responses on the Decisional Control Questionnaire

\begin{tabular}{|c|c|c|}
\hline Question & Response & Percentage \\
\hline \multirow{5}{*}{$\begin{array}{l}\text { Who made the decision for you to enter an } \\
\text { assisted living facility? }\end{array}$} & Self & 61 \\
\hline & Children & 50 \\
\hline & Doctor & 22 \\
\hline & Spouse & 11 \\
\hline & Friend & 6 \\
\hline \multirow{2}{*}{$\begin{array}{l}\text { Did you feel you were involved in the } \\
\text { decision to enter the assisted living facility? }\end{array}$} & Yes & 72 \\
\hline & No & 28 \\
\hline \multirow{4}{*}{$\begin{array}{l}\text { Please describe your involvement in the } \\
\text { decision to enter the assisted living facility. }\end{array}$} & Visited facilities & 33 \\
\hline & Made the decision & 28 \\
\hline & $\begin{array}{l}\text { Involved in } \\
\text { discussions }\end{array}$ & 28 \\
\hline & None & 28 \\
\hline \multirow{5}{*}{$\begin{array}{l}\text { How involved was your family in making the } \\
\text { decision to enter assisted living? }\end{array}$} & Very (Made decision) & $61(28)$ \\
\hline & $\begin{array}{l}\text { Did legwork or helped } \\
\text { move }\end{array}$ & 17 \\
\hline & Minimal & 11 \\
\hline & Not at all & 6 \\
\hline & No family & 11 \\
\hline \multirow{5}{*}{$\begin{array}{l}\text { Who was involved in the decision to enter } \\
\text { assisted living? }\end{array}$} & Self & 44 \\
\hline & Children & 67 \\
\hline & Doctor & 39 \\
\hline & Spouse & 17 \\
\hline & Friends & 6 \\
\hline \multirow{2}{*}{$\begin{array}{l}\text { Do you wish you were more involved in the } \\
\text { decision to relocate to assisted living? }\end{array}$} & Yes & 17 \\
\hline & No & 83 \\
\hline \multirow[t]{2}{*}{ Were you willing to move to assisted living? } & Yes & 94 \\
\hline & No & 6 \\
\hline \multirow{2}{*}{$\begin{array}{l}\text { Have you accepted the decision to move into } \\
\text { assisted living? }\end{array}$} & Yes & 94 \\
\hline & No & 6 \\
\hline
\end{tabular}

Note: Percentages may not add up to 100 due to multiple responses by participants. 
Table 6

Percent of Assisted Living Sample Reporting Various Reasons for Entering Assisted Living $\underline{\text { Facilities }}$

\begin{tabular}{lc}
\hline Reason for entering Assisted Living Facility & Percent of Sample Reporting \\
\hline Needed more assistance & 44 \\
Medical Problem (e.g., stroke) & 39 \\
Others made the decision & 33 \\
Cost of home healthcare & 11 \\
No other choice & 11 \\
To assist or relieve burden from family & 6 \\
Move closer to family & 6 \\
Death of Spouse & 6 \\
Increased Security & 6 \\
\hline
\end{tabular}

Note: Percentages do not add up to 100 due to multiple responses by participants. 
Table 7

Adjustment to Assisted Living

Percent of Community Sample Reporting Various Circumstances Under Which They Would Consider Entering Assisted Living Facilities

\begin{tabular}{lc}
\hline Circumstances & Percent of Sample Reporting \\
\hline Inability to care for self or live alone & 42 \\
If no other arrangements could be made and & 21 \\
had no one else to provide care & 16 \\
Never, under no circumstances & 11 \\
Inability to maintain home & 11 \\
Inability to walk or drive & 5 \\
Would move to assisted living but can't due to & 5 \\
cost & \\
\hline Looking for assisted living in near future & Percentages do not add up to 100 due to multiple responses by participants.
\end{tabular}

Note: Percentages do not add up to 100 due to multiple responses by participants. 
Table 8

Adjustment to Assisted Living 75

Variable Means, Standard Deviations, and Ranges, by Group and Time Period

\begin{tabular}{|c|c|c|c|c|c|c|}
\hline \multirow[b]{2}{*}{ Variable } & \multicolumn{3}{|c|}{ Assisted Living Residents } & \multicolumn{3}{|c|}{ Community Residents } \\
\hline & $\begin{array}{c}\text { Time } 1 \\
(\mathrm{~N}=18)\end{array}$ & $\begin{array}{c}\text { Time } 2 \\
(\mathrm{~N}=18)\end{array}$ & $\begin{array}{c}\text { Time } 3 \\
(\mathrm{~N}=16)\end{array}$ & $\begin{array}{c}\text { Time } 1 \\
(\mathrm{~N}=19)\end{array}$ & $\begin{array}{c}\text { Time } 2 \\
(\mathrm{~N}=19)\end{array}$ & $\begin{array}{l}\text { Time } 3 \\
(\mathrm{~N}=19)\end{array}$ \\
\hline \multirow{3}{*}{ IADLS } & 11.44 & 10.67 & 10.43 & 11.95 & 11.89 & 11.89 \\
\hline & 2.83 & 3.56 & 3.86 & 4.25 & 3.70 & 4.33 \\
\hline & $5-15$ & $2-15$ & $5-16$ & $0-15$ & $1-15$ & $1-15$ \\
\hline \multirow{3}{*}{ Health } & 2.72 & 2.72 & 2.56 & 2.79 & 2.74 & 2.89 \\
\hline & 0.57 & 0.89 & 0.89 & 0.92 & 0.81 & 0.88 \\
\hline & $2-4$ & $1-4$ & $1-4$ & $1-4$ & $1-4$ & $1-4$ \\
\hline \multirow{3}{*}{ GDS15 } & 5.61 & 5.72 & 5.25 & 4.00 & 3.68 & 4.32 \\
\hline & 3.27 & 3.30 & 2.93 & 2.93 & 2.75 & 3.77 \\
\hline & $1-12$ & $1-12$ & $1-11$ & $0-11$ & $1-10$ & $0-12$ \\
\hline \multirow{3}{*}{ LSI-Z } & 12.72 & 12.28 & 12.19 & 16.32 & 17.00 & 17.95 \\
\hline & 4.06 & 5.58 & 4.97 & 5.65 & 6.20 & 6.63 \\
\hline & $5-21$ & $1-23$ & 4-24 & 4-24 & $6-25$ & $7-26$ \\
\hline \multirow{3}{*}{ POMS-SF } & 53.56 & 50.83 & 51.81 & 41.95 & 39.63 & 42.16 \\
\hline & 18.43 & 19.28 & 21.51 & 25.91 & 29.21 & 30.91 \\
\hline & $24-84$ & $21-84$ & $15-92$ & $11-100$ & $9-126$ & $9-100$ \\
\hline \multirow{3}{*}{ BAI } & 15.28 & 13.72 & 15.25 & 9.11 & 8.74 & 9.32 \\
\hline & 10.62 & 9.79 & 10.55 & 10.86 & 8.55 & 8.31 \\
\hline & $3-43$ & $3-35$ & $1-30$ & $0-34$ & $0-28$ & $0-30$ \\
\hline \multirow{3}{*}{$\begin{array}{l}\text { DCS-SF } \\
\text { Desirability }\end{array}$} & 67.00 & 67.72 & 66.81 & 67.79 & 67.63 & 67.58 \\
\hline & 5.19 & 4.52 & 6.32 & 4.59 & 5.95 & 5.21 \\
\hline & $57-78$ & $60-77$ & $50-77$ & $59-80$ & $57-80$ & $58-80$ \\
\hline \multirow{3}{*}{$\begin{array}{l}\text { DCS-SF } \\
\text { Expectancy }\end{array}$} & 57.50 & 58.33 & 57.25 & 58.32 & 60.11 & 61.47 \\
\hline & 6.37 & 5.71 & 6.41 & 8.62 & 9.98 & 8.24 \\
\hline & $44-69$ & $51-71$ & $49-71$ & $39-72$ & $45-78$ & $45-75$ \\
\hline \multirow{3}{*}{$\begin{array}{l}\text { Functional } \\
\text { Support }\end{array}$} & 98.50 & 111.89 & 106.44 & 165.11 & 187.63 & 175.05 \\
\hline & 61.95 & 68.03 & 63.23 & 89.91 & 120.27 & 124.97 \\
\hline & $28-285$ & $37-285$ & $34-294$ & $18-335$ & $19-416$ & $19-464$ \\
\hline \multirow{3}{*}{ Network Support } & 51.28 & 57.67 & 52.56 & 94.74 & 103.11 & 88.63 \\
\hline & 28.38 & 34.52 & 30.14 & 52.92 & 61.42 & 59.64 \\
\hline & $17-133$ & 21-149 & $20-144$ & $11-210$ & $11-222$ & $11-228$ \\
\hline \multirow{3}{*}{ Loss } & 2.67 & 1.00 & 1.63 & 1.26 & 2.00 & 1.58 \\
\hline & 2.89 & 2.52 & 2.45 & 2.64 & 3.09 & 2.48 \\
\hline & $0-7$ & $0-9$ & $0-7$ & $0-7$ & $0-11$ & $0-6$ \\
\hline
\end{tabular}

Each cell contains the mean, standard deviation, and range obtained by the samples for the designated variable. 
Table 9

Adjustment to Assisted Living 76

Results of Repeated Measures ANOVA's, by Group.

\begin{tabular}{|c|c|c|c|c|c|}
\hline Variable & Group & $F$ value & $P$ value & $\begin{array}{r}\text { Partial Et } \\
\text { squared }\end{array}$ & Power \\
\hline \multirow{2}{*}{ IADLS } & Assisted Living & 0.84 & 0.44 & 0.05 & 0.18 \\
\hline & Community & 0.01 & 0.99 & 0.00 & 0.05 \\
\hline \multirow{2}{*}{ Health } & Assisted Living & 0.20 & 0.82 & 0.01 & 0.08 \\
\hline & Community & 0.57 & 0.57 & 0.03 & 0.14 \\
\hline \multirow{2}{*}{ GDS15 } & Assisted Living & 0.13 & 0.88 & 0.01 & 0.07 \\
\hline & Community & 0.91 & 0.41 & 0.05 & 0.20 \\
\hline \multirow{2}{*}{ LSI-Z } & Assisted Living & 0.02 & 0.98 & 0.00 & 0.05 \\
\hline & Community & 1.67 & 0.20 & 0.09 & 0.33 \\
\hline \multirow{2}{*}{ POMS-SF } & Assisted Living & 0.75 & 0.48 & 0.05 & 0.17 \\
\hline & Community & 0.38 & 0.68 & 0.02 & 0.11 \\
\hline \multirow{2}{*}{ BAI } & Assisted Living & 1.00 & 0.38 & 0.06 & 0.21 \\
\hline & *Community & 0.21 & 0.82 & 0.01 & 0.08 \\
\hline
\end{tabular}

*Significant at .05 level. 
Table 10

Adjustment to Assisted Living 77

$\underline{\text { Results of ANCOVA's on Adjustment Variables, by Time Period }}$

\begin{tabular}{|c|c|c|c|c|c|}
\hline Variable & Time & F- value & $\mathrm{p}$-value & $\begin{array}{c}\text { Partial Eta } \\
\text { squared }\end{array}$ & Power \\
\hline \multirow{3}{*}{ IADLS } & 1 & 0.16 & 0.69 & 0.01 & 0.07 \\
\hline & 2 & 0.67 & 0.42 & 0.02 & 0.13 \\
\hline & 3 & 1.28 & 0.27 & 0.04 & 0.20 \\
\hline \multirow{3}{*}{ Health } & 1 & 0.84 & 0.37 & 0.03 & 0.15 \\
\hline & 2 & 0.00 & 0.96 & 0.00 & 0.05 \\
\hline & 3 & 0.92 & 0.34 & 0.03 & 0.15 \\
\hline \multirow{3}{*}{ GDS15 } & 1 & 0.34 & 0.57 & 0.01 & 0.09 \\
\hline & 2 & 1.58 & 0.22 & 0.05 & 0.23 \\
\hline & 3 & 1.06 & 0.31 & 0.03 & 0.17 \\
\hline \multirow{3}{*}{ LSI-Z } & 1 & 1.59 & 0.22 & 0.05 & 0.23 \\
\hline & 2 & 3.94 & 0.06 & 0.11 & 0.49 \\
\hline & 3 & 7.38 & 0.01 & 0.19 & 0.75 \\
\hline \multirow{3}{*}{ POMS-SF } & 1 & 0.65 & 0.43 & 0.02 & 0.12 \\
\hline & 2 & 1.15 & 0.29 & 0.03 & 0.18 \\
\hline & 3 & 1.40 & 0.25 & 0.04 & 0.21 \\
\hline \multirow{3}{*}{ BAI } & 1 & 1.38 & 0.25 & 0.04 & 0.21 \\
\hline & 2 & 2.14 & 0.15 & 0.06 & 0.30 \\
\hline & 3 & 3.29 & 0.08 & 0.10 & 0.42 \\
\hline
\end{tabular}

Note: All F-values obtained on univariate analysis of variance with functional support and network size as covariates. 
Table 11

Adjustment to Assisted Living 78

Results of ANCOVA's on Control Discrepancy, by Time Period

\begin{tabular}{|c|c|c|c|c|c|c|c|c|}
\hline & \multicolumn{2}{|c|}{ Assisted Living } & \multicolumn{2}{|c|}{ Community } & \multirow[b]{2}{*}{ F-value } & \multirow[b]{2}{*}{ P-value } & \multirow{2}{*}{$\begin{array}{c}\text { Partial } \\
\text { Eta } \\
\text { squared }\end{array}$} & \multirow[b]{2}{*}{ Power } \\
\hline & Mean & $\mathrm{SD}$ & Mean & $\mathrm{SD}$ & & & & \\
\hline $\begin{array}{l}\text { Discrepancy } \\
\text { Time } 1\end{array}$ & 9.50 & 5.60 & 9.47 & 7.27 & 0.05 & 0.83 & 0.00 & 0.06 \\
\hline $\begin{array}{l}\text { Discrepancy } \\
\text { Time } 2\end{array}$ & 9.39 & 5.53 & 7.89 & 8.70 & 0.76 & 0.39 & 0.02 & 0.14 \\
\hline $\begin{array}{l}\text { Discrepancy } \\
\text { Time } 3\end{array}$ & 9.56 & 5.22 & 6.11 & 6.46 & 4.86 & 0.04 & 0.14 & 0.57 \\
\hline
\end{tabular}

Note: All F-values obtained on univariate analysis of variance with functional support and network size as covariates. 
Table 12

Adjustment to Assisted Living 79

Mean Differences Between Groups on Adjustment Change Scores, by Time Period

\begin{tabular}{|c|c|c|c|c|c|c|c|c|}
\hline & \multicolumn{2}{|c|}{$\begin{array}{c}\text { Assisted } \\
\text { Living }\end{array}$} & \multicolumn{2}{|c|}{ Community } & \multirow[b]{2}{*}{ F value } & \multirow[b]{2}{*}{$P$ value } & \multirow{2}{*}{$\begin{array}{l}\text { Partial } \\
\text { Eta } \\
\text { squared }\end{array}$} & \multirow[b]{2}{*}{ Power } \\
\hline & Mean & SD & Mean & SD & & & & \\
\hline $\begin{array}{l}\text { IADLS1- } \\
\text { IADLS2 }\end{array}$ & -0.41 & 2.25 & 0.39 & 1.68 & 2.25 & 0.14 & 0.06 & 0.31 \\
\hline $\begin{array}{l}\text { IADLS2- } \\
\text { IADLS3 }\end{array}$ & -0.25 & 2.59 & 0.21 & 2.51 & 0.28 & 0.60 & 0.01 & 0.08 \\
\hline $\begin{array}{l}\text { IADLS1- } \\
\text { IADLS3 }\end{array}$ & -0.45 & 2.99 & 0.38 & 1.84 & 1.00 & 0.33 & 0.03 & 0.16 \\
\hline Health1-Health2 & 0.02 & 0.76 & -0.02 & 0.46 & 0.05 & 0.83 & 0.00 & 0.06 \\
\hline Health2-Health3 & -0.14 & 0.81 & 0.12 & 0.60 & 1.19 & 0.28 & 0.04 & 0.19 \\
\hline Health1-Health3 & -0.14 & 0.65 & 0.12 & 0.72 & 1.24 & 0.28 & 0.04 & 0.19 \\
\hline GDS1-GDS2 & 0.48 & 2.84 & -0.46 & 1.61 & 0.63 & 0.43 & 0.02 & 0.12 \\
\hline GDS2-GDS3 & -0.21 & 3.05 & 0.18 & 2.27 & 0.18 & 0.67 & 0.01 & 0.07 \\
\hline GDS1-GDS3 & -0.20 & 1.99 & 0.17 & 2.45 & 0.24 & 0.63 & 0.01 & 0.08 \\
\hline LSI1-LSI2 & -0.55 & 3.63 & 0.52 & 3.19 & 2.61 & 0.12 & 0.07 & 0.35 \\
\hline LSI2-LSI3 & -1.14 & 3.84 & 0.96 & 4.29 & 2.30 & 0.14 & 0.07 & 0.31 \\
\hline LSI1-LSI3 & -1.01 & 3.44 & 0.85 & 4.03 & 2.10 & 0.16 & 0.06 & 0.29 \\
\hline POMS1-POMS2 & 0.33 & 16.19 & -0.31 & 11.91 & 0.00 & 0.96 & 0.00 & 0.05 \\
\hline POMS2-POMS3 & 1.02 & 16.22 & -0.86 & 16.32 & 0.12 & 0.74 & 0.00 & 0.06 \\
\hline POMS1-POMS3 & -0.99 & 12.20 & 0.84 & 13.29 & 0.18 & 0.68 & 0.01 & 0.07 \\
\hline BAI1-BAI2 & 0.13 & 4.76 & -0.12 & 3.40 & 0.12 & 0.73 & 0.00 & 0.06 \\
\hline BAI2-BAI3 & 1.10 & 7.04 & -0.93 & 2.68 & 1.35 & 0.25 & 0.04 & 0.20 \\
\hline BAI1-BAI3 & 0.91 & 5.48 & -0.77 & 3.23 & 1.26 & 0.27 & 0.04 & 0.19 \\
\hline
\end{tabular}


Table 13

Adjustment to Assisted Living 80

Correlations Between Decisional Control and Adjustment Variables in Assisted Living Sample, by Time Period

\begin{tabular}{lccc}
\hline & $\begin{array}{c}\text { Perceived Decisional } \\
\text { Control Time 1 }\end{array}$ & $\begin{array}{c}\text { Perceived Decisional } \\
\text { Control Time 2 }\end{array}$ & $\begin{array}{c}\text { Perceived Decisional } \\
\text { Control Time 3 }\end{array}$ \\
\hline GDS15 Time 1 & $-.50^{*}$ & -.08 & -.34 \\
GDS15 Time 2 & & & \\
GDS15 Time 3 & .40 & .30 & .06 \\
\hline LSI-Z Time 1 & & & \\
LSI-Z Time 2 & & & \\
LSI-Z Time 3 & -.31 & -.23 & -.29 \\
\hline POMS-SF Time 1 & & & \\
POMS-SF Time 2 & & & \\
POMS-SF Time 3 & -.30 & -.38 & \\
\hline BAI Time 1 & & & \\
BAI Time 2 & & & \\
BAI Time 3 & & & \\
\hline
\end{tabular}

* Correlation is significant at the .05 level (1-tailed). 
Table 14

Adjustment to Assisted Living 81

Correlations Between Desired and Experienced Control and Adjustment Variables in Full Sample, by Time Period

\begin{tabular}{|c|c|c|c|c|c|c|}
\hline & $\begin{array}{l}\text { Desired } \\
\text { Control } \\
\text { Time } 1 \\
\end{array}$ & $\begin{array}{l}\text { Actual } \\
\text { Control } \\
\text { Time } 1 \\
\end{array}$ & $\begin{array}{l}\text { Desired } \\
\text { Control } \\
\text { Time } 2 \\
\end{array}$ & $\begin{array}{l}\text { Actual } \\
\text { Control } \\
\text { Time } 2 \\
\end{array}$ & $\begin{array}{l}\text { Desired } \\
\text { Control } \\
\text { Time } 3 \\
\end{array}$ & $\begin{array}{l}\text { Actual } \\
\text { Control } \\
\text { Time } 3 \\
\end{array}$ \\
\hline GDS15 Time 1 & $-.31 *$ & $-.55 * *$ & & & & \\
\hline GDS15 Time 2 & & & $-.31 *$ & $-.46 * *$ & & \\
\hline GDS15 Time 3 & & & & & $-.54 * *$ & $-.76^{* *}$ \\
\hline LSI-Z Time 1 & .21 & $.44 * *$ & & & & \\
\hline LSI-Z Time 2 & & & .11 & $.47 * *$ & & \\
\hline LSI-Z Time 3 & & & & & $.46 * *$ & $.74 * *$ \\
\hline POMS-SF Time 1 & -.24 & $-.45 * *$ & & & & \\
\hline POMS-SF Time 2 & & & -.24 & $-.50 * *$ & & \\
\hline POMS-SF Time 3 & & & & & $-.60 * *$ & $-.79 * *$ \\
\hline BAI Time 1 & -.21 & -.27 & & & & \\
\hline BAI Time 2 & & & $-.29 *$ & $-.42 * *$ & & \\
\hline BAI Time 3 & & & & & $-.49 * *$ & $-.51 * *$ \\
\hline
\end{tabular}

*Correlation is significant at .05 level (1-tailed).

**Correlation is significant at the .01 level (1-tailed). 
Table 15

Correlations Between Perceived Decisional Control and Health Variables in Assisted Living Sample, by Time Period

IADLS Health

Time 1

Perceived Decisional Control

0.16

$-0.41^{*}$

Time 2

Perceived Decisional Control

0.26

$-0.06$

Time 3

$\begin{array}{lll}\text { Perceived Decisional Control } & 0.19 & -0.64^{* *}\end{array}$

${ }^{*}$ Correlation is significant at .05 level (1-tailed).

**Correlation is significant at the .01 level (1-tailed). 
Table 16

Adjustment to Assisted Living

Correlations Between Desired and Expected Control and Health Variables in Full Sample, by Time Period

Desired Control

Actual Control

Time 1

\begin{tabular}{lcc} 
IADLS Score & 0.03 & $0.37^{*}$ \\
\hline Health & -0.23 & $-0.51^{* *}$ \\
\hline
\end{tabular}

Time 2

IADLS Score

0.11

$0.35^{*}$

Health

$-0.20$

$-0.52 * *$

Time 3

\begin{tabular}{lcc}
\hline IADLS Score & 0.12 & 0.23 \\
\hline Health & -0.22 & -0.25
\end{tabular}

*Correlation is significant at .05 level (1-tailed).

**Correlation is significant at the .01 level (1-tailed). 
Figure 1.

Graphs of Adjustment Variables Over the Three Time Periods, by Group.
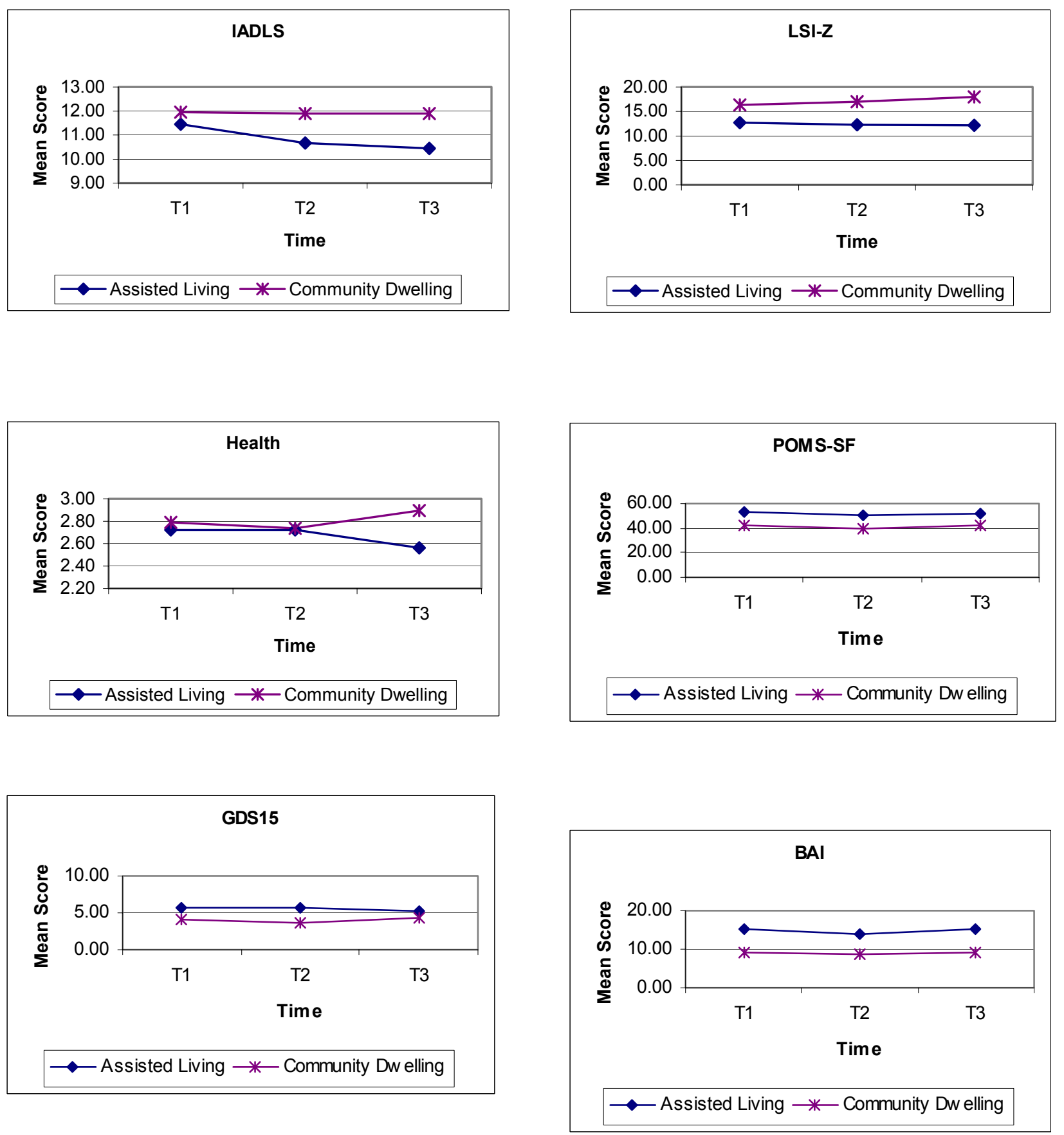


\section{Appendix A}

\section{Demographic Questionnaire}

Please complete the following information.

Age:

Gender (Circle One): Male Female

Ethnicity

Marital Status

Do you currently live with someone? Yes No

If yes, with whom do you live?

Do you have any chronic or acute medical conditions at this time? Yes No

If yes, please describe:

Are you currently taking any prescription or over the counter drugs? Yes No

If yes, please list the drugs you are taking:

In your opinion, why are you entering an assisted living facility at this time? (For Assisted living group only)

Under what conditions would you consider entering an Assisted Living Facility? (For Community Group only) 


\section{Appendix B}

\section{Questionnaire on Decisional Involvement}

Who made the decision for you to enter an assisted living facility?

Did you feel you were involved in the decision to enter the assisted living facility? Yes No How?

Please describe your involvement in the decision to enter the assisted living facility.

How involved was your family in making the decision for you to enter an assisted living facility?

Who was involved in the decision to enter assisted living (e.g., son, doctor, spouse)?

Do you wish you were more involved in the decision to relocate to assisted living?

Were you willing to move to assisted living?

Have you accepted the decision to move into assisted living? 


\section{Appendix C \\ Perceived Decisional Control Questionnaire}

Adjustment to Assisted Living 87

1. Was it your decision to come live in assisted living?

$\begin{array}{ccc}1 & 2 & 3 \\ \text { No } & & \text { Yes }\end{array}$

2. Did others consult with you much about the decision to come stay in assisted living?

$\begin{array}{ccc}1 & 2 & 3 \\ \text { No } & & \text { Yes }\end{array}$

3. Do you feel that you influenced the decision to come here?

$\begin{array}{ccc}1 & 2 & 3 \\ \text { No } & & \text { Yes }\end{array}$

4. How much input would you say that you had in the decision to come live in assisted living?

1

None
2

3

A great deal 


\section{Appendix D}

\section{Self-Rated Health Questionnaire}

How would you rate your health (circle one)?

$\begin{array}{cccc}1 & 2 & 3 & 4 \\ \text { Excellent } & \text { good } & \text { fair } & \text { poor }\end{array}$




\section{Appendix E}

\section{Geriatric Depression Scale - 15}

The following questions ask you about your mood over the past week. Choose either yes or no depending on how you felt during the past week.

1. Are you basically satisfied with your life?........................................Yes No

2. Have you dropped many of your activities and interests?..................Yes No

3. Do you feel that your life is empty?........................................................Yes No

4. Do you often get bored?..................................................................................Yes No

5. Are you in good spirits most of the time?..............................................Yes No

6. Are you afraid that something bad is going to happen to you?..........Y Yes No

7. Do you feel happy most of the time?..........................................................Yes No

8. Do you often feel helpless?.....................................................................Yes No

9. Do you prefer to stay at home, rather than going out and doing new

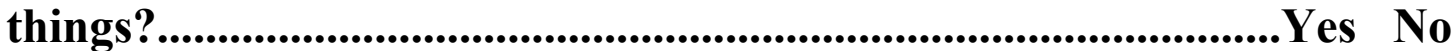

10. Do you feel you have more problems with memory than most?.......Yes No

11. Do you think it is wonderful to be alive?.........................................Yes No

12. Do you feel pretty worthless the way you are now?............................ Yes No

13. Do you feel full of energy?...........................................................................Yes No

14. Do you feel that your situation is hopeless?...........................................Yes No

15. Do you think that most people are better off than you are?.............. Yes No 


\section{Lisa Whipple Drozdick}

Adjustment to Assisted Living 90

\section{CURRICULUM VITAE}

March 2003

EDUCATION

\begin{tabular}{ll}
\hline $\begin{array}{l}\text { Clinical Internship } \\
8 / 99-8 / 00\end{array}$ & $\begin{array}{l}\text { Clinical Psychology Intern - Geropsychology Specialty Track } \\
\text { South Texas Veterans Healthcare System, San Antonio, Texas }\end{array}$ \\
$\begin{array}{l}\text { Graduate } \\
\text { 8/97-5/03 }\end{array}$ & $\begin{array}{l}\text { Doctoral Candidate } \\
\text { Adult Clinical Psychology Ph.D. Program, West Virginia University }\end{array}$ \\
8/94-5/97 & $\begin{array}{l}\text { Master of Arts degree in Psychology } \\
\text { Adult Clinical Psychology Ph.D. Program, West Virginia University }\end{array}$ \\
Undergraduate & $\begin{array}{l}\text { Bachelor of Science degree in Psychology } \\
\text { 8/90-5/94 }\end{array}$ \\
& Major in Psychology Minor in History, Texas A\&M University
\end{tabular}

CLINICAL EXPERIENCE

5/02-Present Senior Research Analyst

The Psychological Corporation, San Antonio, TX

12/00-5/02 Research Analyst

The Psychological Corporation, San Antonio, TX

8/99-8/00 Clinical Psychology Intern, Geropsychology Specialty

South Texas Veterans Healthcare System, San Antonio, Texas

7/97-7/98 Community Mental Health Center Practicum Student

Valley Comprehensive CMHC, Morgantown, West Virginia

8/96-7/97 Inpatient Psychogeriatric Practicum Student

Hopemont Hospital, Department of Psychology, Terra Alta, West Virginia

8/96-5/97 Graduate Student Therapist

Quin Curtis Center - West Virginia University, Morgantown, WV

7/95-8/96 Psychiatric Inpatient Practicum Student

William R. Sharpe, Jr. State Hospital, Weston, WV

TEACHING EXPERIENCE

8/98-5/99 Graduate Teaching Assistant: Introduction to Psychology

West Virginia University, Department of Psychology, Morgantown, WV

1/98-5/98 Graduate Teaching Assistant/Instructor: Behavioral Assessment II

West Virginia University, Department of Psychology, Morgantown, WV

8/97-12/97 Course Instructor: Religion and Clinical Psychology

West Virginia University, Department of Psychology, Morgantown, WV

1/97-5/97 Graduate Teaching Assistant: Child Behavior Modification

West Virginia University, Department of Psychology, Morgantown, WV

1/96-5/96 Course Instructor: Behavioral Medicine

West Virginia University, Department of Psychology, Morgantown, WV 